\title{
Epistemic Modality De Re
}

\author{
SETH YALCIN \\ University of California, Berkeley
}

\begin{abstract}
Focusing on cases which involve binding into epistemic modals with definite descriptions and quantifiers, I raise some new problems for standard approaches to all of these expressions. The difficulties are resolved in a semantic framework that is dynamic in character. I close with a new class of problems about de re readings within the scope of modals.
\end{abstract}

\section{Modality and Description Revisited}

It is a familiar point, emphasized by Kripke (1972/1980), that we can use a definite description to designate an object and then go on to truly say, of the object designated, that it might have failed to have the properties required by the very description used to pick the object out. Thus, talking about some election, we can say:

(1) The winner might have lost.

(2) The winner might not have been the winner.

On the preferred reading of (1), the definite description takes wide scope relative to the modal. ${ }^{1}$ The description picks out the individual who is the winner relative to the evaluation world, and the sentence serves to express the idea that that individual-Nixon, say - might have lost. Glossing this reading with the tools familiar from quantified modal logic, the sentence is true at a world $w$ iff the winner $x$ in $w$ is such that there is some possible world $w^{\prime}$ relevantly accessible from $w$ such that $x$ lost in $w^{\prime}$. (Similarly for (2).) As usually understood, this gloss depends on the intelligibility of the idea that objects may have non-

1. Or so it seems. Another possible analysis (the in-scope de re analysis) is discussed in Section 12 below.

Contact: Seth Yalcin <yalcin@berkeley.edu> 
trivial modal properties independently of how they are specified-i.e., on the idea that there are nontrivial de re modal properties. Kripke was concerned (inter alia) to stand up for the respectability of this idea. He was concerned to shift the burden of proof onto those who would deny its intelligibility or plausibility, by supplying a range of ordinary examples seemingly well-characterized in terms of it.

Like many, I think Kripke largely succeeded in this goal. I am not interested in pressing some new case against the coherence of de re modal predication in general. But I do wish to highlight an important class of cases wherein what might or must be the case with an object does seem to depend on the way that the object is specified. These are cases where the flavor of modality employed in talking about the object-the flavor of might and must at issue-is what gets called epistemic modality in the literature. Observe the contrast between (1) and (2), and between (3) and (4):

(3) \# The winner possibly lost.

(4) \# The winner might not be the winner.

The modals in these sentences can only be read as epistemic. The sentences seem not to have any true readings. In particular, neither sentence has a true reading wherein the epistemic modal takes narrow scope relative to the definite description in subject position. These sentences have a ring of incoherence or self-defeat about them. To a first approximation, it seems that if we use a description the $F$ to pick out some thing $x$, we cannot go on to truly say that it is possible, in the epistemic sense of 'possible', that the so-designated $x$ is not $F$. Granting that there is a clear sense in which the winner might not have been the winner, that the winner could have failed to be the winner, there seems not to be any clear sense in which the winner might not be the winner, or possibly is the loser. Insofar as these claims make any sense, they seem false: the winner must, of course, be the winner.

(To say that the winner must be the winner is not to say that it is a necessary truth that the person who won is the winner; it is not to say that the person who in fact won wins in every possible world. Rather, the must here is epistemic. The nature of this must is part of our topic of inquiry.)

Kripke's great success in isolating and interpreting the non-epistemic reading of the modalities present in sentences like (1) and (2) seems to have distracted from the basic fact that when we consider syntactically simpler sentences like (3) and (4), where the modals are unambiguously epistemic, the sentences are in 
fact marked, and lack true readings. His success also seems to have obscured the fact that the modals in (1) and (2), when interpreted as epistemic, yield sentences that lack true readings. ${ }^{2,3}$

Suppose we tentatively use [the $x: F x$ ] to represent the logical form of a definite description the $F$, formalizing it as a variable binding device that is syntactically apt to combine with an open sentence having the relevant variable free (the description's nuclear scope); and let us henceforth reserve the diamond and box exclusively for representing epistemic possibility and necessity modals, respectively. Then the problem examples so far reviewed roughly fit the following shape:

[the $x: F x](\diamond \neg F x)$

Observe the description takes scope outside the epistemic modal and binds a variable within the modal's scope. I will call cases where a variable within the scope of an epistemic modal is bound from outside of that modal cases of binding in.

The initial generalization, then, is that instances of binding in of this form are marked, and never true. As I review in the next section, standard ways of thinking about modality and description leave this fact unexplained. One aim of what follows is to draw out what lessons are to be learned here about epistemic modality and about descriptive reference.

\section{Quandary for Standard Approaches}

Start with a textbook Kripke-style relational semantics for modals. The influential account of Kratzer $(1981$; 1991; 2012) is, in relevant respects, a development of this kind of approach; see also Lewis (1979). On this approach, natural language modal words generally express quantification over possible worlds. Possibility modals-e.g., may, might, can, possibly - express existential quantification. Necessity modals-e.g., must, have to, necessarily-express universal quantifica-

2. Not to suggest that Kripke himself was generally unaware of epistemic readings of modals. He flags this kind of reading in various places; see for example Kripke (1972/1980: 103, 124-5, 143).

3. Incidentally: there is a way of taking (3) and (4) so that what they convey is "The person who is being taken to be the winner might not, after all, be the winner". (On this kind of construal, one can even make sense of "The winner is not in fact the winner".) I take it that this construal does not correspond to a bonafide reading, but rather corresponds to a reinterpretation that charitable speakers reach for when presented with a sentence whose default semantic interpretation is marked. 
tion. 4 The fact that these modal words can frequently take different readingsdeontic, teleological, epistemic, nomological, and so on-is explained by letting the quantification these modals express be relative to an accessibility relation, or to a choice of restriction. Each flavor of modality corresponds to a distinctive kind of restriction, or different accessibility relation, and the restriction or accessibility relation in play in any given case will often be supplied tacitly by context. Epistemic modals are thus epistemic simply in virtue of the fact that the quantification they express is restricted to some class of epistemically accessible worlds. It is controversial, among theorists who favor an analysis along these lines, exactly whose knowledge, or what information, is supposed to settle what possibilities count as epistemically accessible for the purposes of evaluating an epistemic modal claim (for relevant problematic data and discussion, see Teller 1972; DeRose 1991; Swanson 2006; Egan 2007; Hawthorne 2007; von Fintel \& Gillies 2008; Dowell 2011; MacFarlane 2011; Yalcin 2011; Willer 2013; Stalnaker 2014; Yanovich 2014; Knobe \& Yalcin 2014; Huvenes 2015; Moss 2015). But we need not take a stand on this matter. Assume for the sake of argument that we have an epistemic accessibility relation $R$ in good standing, perhaps fixed as some elaborate function of context. We want to consider a textbook relational semantics for epistemic possibility and necessity modals stated in terms of some such relation:

$w \vDash \diamond \phi$ iff there is some $w^{\prime}$ such that $w R w^{\prime}$ and $w^{\prime} \vDash \phi$

$w \vDash \square \phi$ iff for all $w^{\prime}$ such that $w R w^{\prime}, w^{\prime} \vDash \phi$

Now there are various well known ways we might model definite descriptions in the context of a modal semantics like this, using models familiar from ordinary quantified modal logic. Two dominant approaches, discussed in more detail below, are modern variants of the analyses proposed by Frege (1892) and by Russell (1905), respectively. Modern Russellian approaches usually hold that definite descriptions are akin to generalized quantifiers; their semantic values are second-order properties. Modern Fregean approaches usually hold that the semantic values of definite descriptions are equivalent to individual concepts (partial functions from worlds or situations to individuals). To a crude first approximation, on both approaches, The $F$ is $G$ is true at $w$ if and only if the thing which is uniquely $F$ in $w$ is also $G$ in $w$. A less crude second approximation would reference additional implicit contextual restrictions.

4. Strictly speaking, Kratzer's own preferred account is more complicated than this-while she holds that modals express quantification over worlds, the quantification invoked is generally more complicated than simply existential or universal quantification. Depending on the modal in question, her semantics will usually call for one or more quantifier alternations. But these differences are orthogonal to the issues of present concern. 
It is not necessary at this stage to go into the details of implementation for either of these views. Packaging any analysis of descriptions along these familiar lines with a textbook possible worlds semantics for epistemic modals of the sort described above, we incorrectly predict that there are contexts where the following sentence has a true binding in reading:

(4) \# The winner might not be the winner.

To see this, consider any context such that the winner, relative to the world $w$ of the context, does not win relative to every world epistemically accessible from $w$. This is a context such that the person who is in fact the winner is not known (or not required by the relevant information) to be the winner (again, in whatever sense of "known", "required by the information", etc. is thought to matter to the notion of accessibility relevant for epistemic modals). A moment's reflection should reveal that this sort of context is not at all unusual. It is simply a context where some ignorance prevails about who exactly the winner is. It is perfectly ordinary not to know who or what exactly answers to a definite description that one uses in a given context-indeed, this kind of ignorance is a paradigm reason for using a definite description in the first place. In such contexts, the binding in reading of (4), wherein the epistemic modal takes narrow scope relative to the definite description subject, is predicted to be true by a textbook relational semantics for epistemic modals plus a textbook Russellian or Fregean analysis of descriptions. This reading is predicted to be a way of expressing roughly the following kind of thought: it is not clear, given the evidence or information available, who the winner is. But (4) cannot serve to express this sort of thought. It is defective, even in contexts where the relevant knowledge or evidence does not settle who the winner is. Moreover, there seems to be no amount of fiddling with context that saves (4). Without some nontrivial further supplementation, a textbook approach to modals and descriptions does not explain the facts.

Another example, to reinforce the point. Let us assume that no one knows who the first person to contract the Dengue virus was, and that the question is not settled by any of the relevantly accessible evidence. This means that the definite description 'the first person to contract the Dengue virus' should have an extension which is non-constant as we evaluate it at the different worlds epistemically accessible from ours. Now, we could report our state of ignorance with one of these:

(5) The first person to contract the Dengue virus-we don't know who that is.

(6) The first person to contract the Dengue virus - the information available does not settle who that is. 
We could also say:

(7) The first person to contract the Dengue virus, whoever that is, is not known to be the first person to contract the virus.

However, we could not say:

(8) \# The first person to contract the Dengue virus (whoever that is) might not be the first person to contract the virus.

Standard approaches to modality and description leave this unexplained, however. On such accounts, (8) should have a reading on which it says the kind of thing that (5)-(7) say. It should have a reading true at a world $w$ just in case:

(9) The first person $x$ to contract the Dengue virus in $w$ is such that there is some world $w^{\prime}$ epistemically accessible from $w$ such that $x$ is not the first person to contract the Dengue virus in $w^{\prime}$

It is not hard to see that these truth-conditions would correctly characterize the stipulated epistemic predicament. Since the evidence leaves open who the first person to contract the virus is, it is not that case that one particular person was the first to get it at every one of our epistemically accessible worlds. No matter who in fact got the virus first, there is an epistemically accessible world where that person did not get the virus first. That, of course, is just what it is, in this formal setting, for ignorance to prevail about who exactly got it first. So if (8) had a truth-condition tantamount to (9), we would find it acceptable in the epistemic predicament just described. But we do not. So it does not have truth-conditions of this sort. So something about the textbook account is not correct.

Notice that we have not leaned on any controversial assumptions about the details of the epistemic accessibility relation. All we require is the uncontroversial assumption that it is possible for a definite description to have a nonconstant extension when evaluated across epistemic alternatives. To reject this assumption within the context of standard approaches to descriptions would be to embrace the view, held by no one, that speakers only use definite descriptions when it is known who or what answers to the description.

Moving beyond textbook accounts, one might seek explanation for these data in more recent theories about the semantics of epistemic modals. But the flurry of new work in this area has overwhelmingly centered on epistemic modality de dicto. The present puzzle concerns binding into epistemic modals, what we might consider a species of epistemic modality de re. Recent semantic theories developed in response to puzzles that arise at the de dicto level leave the 
present problem untouched. For example, we come no closer to a solution if we suppose, in the spirit of Stephenson (2007) or Egan (2007), that epistemic accessibility should be construed as a relation between centered worlds rather than possible worlds, or that unembedded epistemic modal sentences express centered world propositions. These moves do not affect the dialectic. The centered worlds technology in these accounts is directed at explaining quite different data. ${ }^{5}$ Neither is the situation improved if we allow that epistemic modals are assessment-sensitive in the style of MacFarlane (2011; 2014): that theory, like the "cloudy contextualism" of von Fintel and Gillies (2011), is motivated primarily by the behavior of unembedded epistemic modal claims. These theories are designed principally with an eye towards making special predictions about the way truth-value judgments about unembedded epistemic modal claims are (or are not) sensitive to the contexts at which the sentences are uttered or assessed. But the present problem does not concern the potential for divergence of truth-value judgments across contexts of assessment; and neither does it appear to have anything to do with more ordinary forms of context-sensitivity, as the defect in sentences like (3) and (4) is robust across arbitrary changes in context.

\section{Controlling Scope}

Before continuing, it is important to reply to a certain kind of deflationary, syntactic response that one might have to the problem. It is widely accepted in the linguistics literature that epistemic modals exhibit a preference for scoping high, and in some cases seem even to require wide scope relative to other scope-taking expressions like quantifiers (see especially von Fintel \& Iatridou 2003). ${ }^{6}$ This naturally prompts the thought that the problem with sentences like (3) and (4) is simply that the epistemic modals in these examples are required, as a matter of syntax, to take widest scope. If so, that would seem to dissolve the problem, for it would mean that the binding configuration which we focus on is not in fact available, grammatically speaking. On this thought, (3) would just be equivalent to (10), and (4) to (11) (understanding the epistemic modals to take wide scope):

5. Namely, apparent intra-world variation in truth value judgments about epistemic modal claims (Egan 2007) and the fact that attitude environments like believes seem to obligatorily shift the domain of worlds that an epistemic modal quantifies over (Hacquard 2006; Stephenson 2007; Yalcin 2007; Anand \& Hacquard 2013).

6. Against von Fintel and Iatridou (2003), Swanson (2010) argues that quantifiers can take scope over epistemic modals within the same clause. I am not entering this debate. In this paper I am not particularly interested in whether there are intra-clausal constraints on the scopal relations between epistemic modal and quantifiers. As will become clear, I mostly exploit obviously multiclausal structures to capture the scopal configurations whose semantics I am interested in. 
(10) \# It is possible that [the winner lost].

(11) \# It might be that [the winner is not the winner].

And there would seem to be no difficulty explaining what is wrong with these sentences, relative to the stipulated scopal configuration. ${ }^{7}$

To respond to this objection, we must take measures to ensure that our epistemic modals really are taking narrow scope relative to the relevant definite descriptions. We can do this by placing the epistemic modals in scope islands - syntactic environments known to prevent (unexceptional) scope-taking expressions from scoping out. A familiar kind of scope island is the relative clause. Observe for instance that while the universal quantifier every customer in (12) can take either wide or narrow scope relative to the indefinite a salesman, the universal quantifier in (13), which is located with a relative clause, cannot take scope over the indefinite:

(12) A friendly salesman greeted every customer. $(\exists>\forall, \forall>\exists)$

(13) A salesman who greeted every customer was friendly. $(\exists>\forall, * \forall>\exists)$

Thus to ensure that the desired scopal order for our target sentences is realized, we can minimally adjust (3), (4), and (8) by placing the epistemic modals in the appropriate relative clauses, as follows:

(14) \# The winner is a person who possibly lost.

(15) \# The winner is a person who might not be the winner.

(16) \# The first person to contract the virus is a person who might not be the first to contract the virus.

Once the epistemic modals are nestled within relative clauses, they are compelled to take narrow scope relative to the corresponding definite description subjects. ${ }^{8}$ We observe nevertheless that (14), (15), and (16) are as defective as (3), (4), and (8).

Further, we can observe that this defect does not owe to some general problem with placing epistemic modals within scope islands, or with binding across these modals per se. There is no general problem with doing either of these things. For example, we have no trouble with:

7. Actually, there remains a difficulty in light of the possibility of in-scope de re readings of the sort described in Section 12 below. I postpone the issue.

8. An alternative analysis of the situation is that the postcopular indefinite actually introduces a layer of quantification of its own, and the modal is compelled to take narrow scope relative to this quantification. I assume the simpler analysis of the main text, as the question how exactly postcopular indefinites work appears to be quite orthogonal to the problems of concern here. 
(17) The winner is a person who might be from California.

(18) The first person to contract the virus is a person who might have interacted with infected birds.

(19) While there can only be one winner, every contestant is a person who might win.

The conclusion is that our problem cannot be blocked by appeal to some general syntactic restrictions on the scope of epistemic modals. Henceforth I will tend to assume that there is no special syntactic reason that the epistemic modals in sentences like (3), (4), and (8) are prevented from taking narrow scope at the relevant level of logical form. But readers skeptical of this should feel free to regard the problem I raise as one specifically about sentences like (14), (15), and (16). Further, such readers should feel free to sprinkle relative clauses as required to modify relevant examples below.

\section{Open Epistemic Contradiction}

On most any theory of definite descriptions, the truth of a sentence of the form [the $x: F x](G x)$ will entail that there is some variable assignment relative to which an open sentence of the following form is true:

$(F x \wedge G x)$

Bringing this elementary point to bear on our target examples, we observe that the truth of a sentence of the form [the $F x$ ] $(\diamond \neg F x)$ would entail that there is some variable assignment relative to which an open sentence of the following form is true:

$$
\text { (20) }(F x \wedge \diamond \neg F x)
$$

It is tempting to suspect that this entailment is at the root of our problem. Perhaps on the correct theory of epistemic modality, there simply cannot be any object $d$ such that on an assignment of $d$ to $x$, the open sentence $(F x \wedge \diamond \neg F x)$ is true relative to that assignment. Or to put the idea in a different way, perhaps the problem is that (on whatever the correct understanding of ' $\diamond$ ' is) the property expressed by the following complex predicate is incoherent, in the sense that nothing falls in its extension regardless of the world of evaluation we consider:

$$
\lambda x(F x \wedge \diamond \neg F x)
$$


That would be to say that this predicate is no more coherent, or capable of satisfaction, than an overtly contradictory predicate, such as $\lambda x(F x \wedge \neg F x)$. The property of being infected and possibly not infected is not a property anything has, or could have.

This general line of thinking would suggest that our problem is connected to the problem about epistemic modals described in Yalcin (2007). That paper discusses sentences like:

(21) \# It is raining and it might not be raining. $(\phi \wedge \diamond \neg \phi)$

These sentences were already much discussed in the dynamic semantics literature, owing to Veltman's work (1985; 1996); see also Groenendijk and Stokhof (1991a), Groenendijk, Stokhof, and Veltman (1996). Prima facie, these sentences seem pragmatically defective, in a fashion akin to Moore-paradoxical sentences. But reflecting on the way that such conjunctions embed, Yalcin (2007) argued that the problem with these sentences is not merely pragmatic. Observing the defective character of sentences like:

(22) \# Suppose it is raining and it might not be.

(23) \# John imagines that it is raining and it might not be raining.

(24) \# If it isn't raining and it might be raining, we should stay home.

I defended the view that in order to explain such facts, $\phi$ should generally be reckoned inconsistent with $\diamond \neg \phi$, and $\neg \phi$ with $\diamond \phi$ (compare again Veltman 1996, who defended a dynamic version of this view; see also Landman 1990). On the view developed, conjunctions of the form

$$
(\phi \wedge \diamond \neg \phi),(\neg \phi \wedge \diamond \phi)
$$

are a kind of contradiction ("epistemic contradiction"). The view requires a nonclassical consequence relation, in order to square the contradictory character of these sentences with the fact that epistemic possibility sentences do not generally entail their prejacents (i.e., $\diamond \phi \notin \phi$ ).

Yalcin (2007) does not discuss binding into epistemic modals, or epistemic contradictions that involve open sentences. But the data reviewed so far suggests it may be fruitful to extend this terminology to such cases. We could try saying that sentences in the shape of (20) are open epistemic contradictions; and we could say that open epistemic contradictions are just as problematic as their closed counterparts. (At least, as they occur in constructions which require, for 
their truth, that the open epistemic contradiction be true relative to some variable assignment.)

This idea would suggest that any sentence requiring an open epistemic contradiction to be true relative to some variable assignment will be defective. That suggestion appears to be borne out by the facts. Most obviously, we can observe that if we have an open epistemic contradiction fully contained within the nuclear scope of a descriptive sentence, the result is indeed defective:

(25) \# The professor is a person who is nice and might not be nice. [the $x: P x](N x \wedge \diamond \neg N x)$

And similarly, if we have something tantamount to such a conjunction within the restrictor position:

(26) \# The professor who might not be a professor is nice. [the $x:(P x \wedge \diamond \neg P x)](N x)$

\section{Quantifying In}

More interestingly, if open epistemic contradictions were the locus of the problem, we would expect that this puzzle can arise in the absence of definite descriptions. It should arise anywhere we have a sentence entailing that an open epistemic contradiction has some witness - for example, various quantified sentences, and sentences containing indefinites. And this is indeed what we observe:

(27) \# Some person who is not infected (is a person who) might be infected.

(28) ?? Some person who might be infected is not infected.9

(29) \# Some person who is not infected and might be infected is quarantined.

(30) \# Every person who is not infected (is a person who) might be infected.

(31) \# Every person who is not infected and might be infected is quarantined.

As in the definite description case, an ordinary relational semantics for epistemic modals does not predict the defect in these sentences. All of these sentences are

9. Some report that this sentence is comparatively less marked than the others. We return to this below. 
predicted to be capable of true readings. Suppose, for example, that there are three people locked in a quarantine room. It is known that exactly one of three is infected, but it is not known who. Then the relevant binding in reading of each of the sentences above should be true in this case. For any person in the quarantine who is not in fact infected, there is some epistemic alternative wherein that person is infected. On a relational view of epistemic modality, that fact would suffice to bestow upon each person in the quarantine the de re epistemic modal property being a person who might be infected. Together with the other basic facts of the case, this will entail the truth of the binding in reading for each of the sentences above. But as in the definite description case, this prediction is a mistake.

One more example, for the sake of variety. Suppose we have five marbles: four white, one black. They are randomly distributed under cups. It is not known which marble is where. We cannot say:

(32) \# A marble which is black and $\left\{\begin{array}{l}\text { possibly } \\ \text { probably }\end{array}\right.$ white is under a cup.

This is puzzling. These sentences should have true readings given a relational semantics for epistemic modals and a standard semantics for the indefinite as an existential quantifier. ${ }^{10}$ But they do not. As in the definite description case, again what we seem to see is that once a variable $x$ is introduced and is constrained to have a value which falls under some predicate $F$ relative to the evaluation world, the value of $x$ is thereby constrained to fall under $F$ relative to any epistemic alternative introduced by a subsequent epistemic modal.

Since open epistemic contradiction seems to be a unifying feature of the problematic examples, and since Yalcin (2007) offers a semantics and definition of consequence that appears to explain the defect arising in connection with closed epistemic contradictions, the question arises whether the theory of that paper, extended in the most obvious way with quantifiers, can predict the problematic data we have so far observed. The answer is negative: the system of Yalcin (2007) is no better off than an ordinary relational semantics in the face of the problems so far discussed. (See the appendix for further discussion.)

10. Note that essentially all of the problems I discuss about epistemic possibility in this paper recur with epistemic modals like probably and likely. I will not generally pause to observe this explicitly. Nor will I attempt to analyze these modals in this paper, owing to considerations of space. (I believe the dynamic system described below can draw upon the resources of Yalcin (2012b) when it comes to probability operators, but I am unable to defend this view here.) 


\section{Departures from Predicate Logic}

Some further problems arise in connection with the logic of the quantifiers. I will mention three. First, consider the sentence:

(33) Not everyone who might be infected is infected. ${ }^{11}$

The sentence is intuitively true relative to the quarantine scenario just described. Now elementary logic teaches that some and every are duals, hence interdefinable in terms of negation. Let us represent these natural language determiners as $\exists$ and $\forall$, respectively. We will take them to be dyadic operators, approximating the (standard) view that determiners semantically combine with a restrictor and a nuclear scope. Then duality is standardly understood to entail:

$$
\neg \forall x(\phi, \psi) \Leftrightarrow \exists x(\phi, \neg \psi)
$$

Given a standard formalization, this would mean that (33) is truth-conditionally equivalent to the comparatively eyebrow-raising (28) (repeated):

(28) ?? Some person who might be infected is not infected.

The classical semantics for the existential quantifier also licenses the swapping of the restrictor and the nuclear scope:

$$
\exists x(\phi, \psi) \Leftrightarrow \exists x(\psi, \phi)
$$

Together with duality, this would mean that (33) is also truth-conditionally equivalent to (27) (repeated):

(27) \# Some person who is not infected is a person who might be infected.

But while most speakers judge (33) to be true relative to the quarantine scenario, they find (27) to be relatively marked and untrue, as already noted. Epistemically modalized complex predicates thus provoke two interconnected questions. The first question is whether to reconsider the duality of universal and existential quantification. The second is whether to reconsider the exchangeability of the restrictor and nuclear scopes of the existential quantifier.

The second problem is this. Problematic sentences like (29), (27), and (28)

11. I am indebted to Declan Smithies for focusing my attention on this kind of sentence. 
would, given standard predicate logic, be entailed by the following pair of sentences:

(34) Every person quarantined is a person who might be infected.

(35) Some person quarantined is not infected.

But obviously, these sentences are perfectly coherent and jointly satisfiable. (Indeed, the quarantine scenario described earlier would be correctly described by these two sentences.) Since we shouldn't like a logic where coherent and satisfiable sentences entail incoherent, unsatisfiable sentences, evidently we want a consequence relation which precludes the possibility that (34) and (35) do in fact entail (27)-(29). But this would seem to require a nonstandard logic for the quantifiers.

The third problem is related. An easy way to bring it out uses the epistemic modal likely. Suppose Jane is a medical student learning about a certain genetic disease. She learns that this disease is extremely rare: only one in a million have it. She also learns that a reliable indicator that a person has this disease is the presence of a certain diamond-shaped birthmark on the scalp. Everyone with this disease has the birthmark; and though it's possible to have the birthmark but not the disease, everyone with this sort of birthmark is a person that is likely to have the disease.

So Jane learns the following two things. First she learns that, since the disease is so rare, any given person is very unlikely to have the disease. Jane would thus be correct to leave lecture thinking to herself: "I probably don't have the disease. One in a million, after all!" Second, she learns that every person with the birthmark is a person who is likely to have the disease. Let us list these two things that Jane now knows, and that could be asserted (by she, or us) given just the information stipulated above:

(36) Jane is not likely to have the disease.

(37) Every person with the birthmark is a person who is likely to have the disease.

Now given textbook predicate logic, these together entail the following conclusion:

(38) Jane does not have the birthmark.

But it would plainly be a mistake - for Jane, or for us - to draw this conclusion from (36) and (37). Jane knows (36) and (37), but she cannot use this knowledge and deduction to arrive at knowledge of (38). If she were able to draw that con- 
clusion, she could use it, together with the fact that everyone with the disease has the birthmark, to conclude that she doesn't have the disease. But she cannot arrive at that conclusion with the merely probabilistic information expressed by (36) and (37). She picked up (36) and (37) from her medical school lectures. But she cannot use the information gleaned from lecture to draw a definitive conclusion about whether she has the birthmark, or has the disease. If she wants to know whether (38) is true, she needs more than just the statistical information picked up in class. She needs to actually check her scalp for the birthmark. At least, she needs to do this if she wants to move beyond the conclusion that she is merely very, very unlikely to have the birthmark, to the (unhedged) conclusion (38), that she does not have the birthmark (cf. Yalcin 2012c).

So (38) does not follow from (36) and (37); (36) and (37) are consistent with the possibility that Jane does have the birthmark. Therefore standard predicate logic does not issue the correct prediction in this case. We have a counterexample to the following classically valid inference pattern:

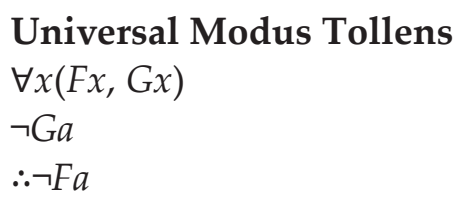

Counterexamples may arise when the material in the position of $G$ is an epistemically modalized complex predicate. ${ }^{12}$

Note the problem recurs with epistemic must. If, instead of (36) and (37), we had (39) and (40) instead:

(39) It is not the case that Jane must have the disease.

(40) Every person with the birthmark is a person who must have the disease.

12. Some may be tempted to argue that the body of information likely is evaluated relative to shifts across (36) and (37) as a function somehow of context, in such a way that the argument from (36) and (37) to (38) is not a real instance of Universal Modus Tollens; we have instead a fallacy of equivocation. See Yalcin (2012c) for a critique of this sort of response, in connection with ordinary Modus Tollens. Below I will offer a motivated compositional semantics for modals and quantifiers which does not require any appeal to pragmatic context-shifting in order to explain the kind of data just reviewed. In a certain precise sense, however, the view developed below is compatible with thought that there is a kind of context-shifting going on in the above counterexample to Universal Modus Tollens. The epistemic modal in the quantified sentence (37) is indeed evaluated relative to a different sort of context than the probability operator in (36), in a particular sense of "context" to be introduced. The operative kind of context-shifting is semantic rather than pragmatic in nature, however. 
(Adjusting the background facts of the case, so that now (40) is true.) From (39) and (40), we still could not draw (38) as a conclusion.

Summarizing, our overall challenge in connection with quantifiers has two related dimensions. The first dimension of the challenge is just to explain why sentences like (27)-(31) and so on strike us as defective in the way that they do. The second dimension of the challenge is to predict the relevant ways - we have reviewed three-in which the logic of quantified sentences departs from the behavior predicted by ordinary classical predicate logic when the quantifiers bind across epistemic modals.

\section{Quantification and Modality as Dynamic}

Our solutions to the puzzles just described will be situated within a dynamic semantics. In a dynamic setting, the meaning of a sentence is given, not as a function from some points of evaluation in a model to truth values (as in an ordinary model-theoretic truth-conditional semantics), but instead as an update operation on a state or body of information. The classic references for this approach to meaning are Kamp (1981) and Heim (1982), with Karttunen (1969) and Stalnaker (1974; 1975; 1978) providing a number of the critical background insights leading to the dynamic shift in perspective.

There is a body of work in the dynamic semantics literature already capable of addressing many of the problems we have highlighted. This is the work that has investigated different ways of integrating the dynamic approach to epistemic modals Veltman introduced (1996) with dynamic approaches to quantification: see Groenendijk et al. (1996), Aloni (2001), Beaver (2001), and many others building on these. Groenendijk et al. (1996), while it does not discuss any of the exact problems presented above, contains a prescient and illuminating discussion of certain cases of binding variables across epistemic modals, and it gives a detailed dynamic semantic treatment of these. Within the system defended, the duality of the quantifiers fails; universal Modus Tollens fails in the kind of case we have described; and their system also predicts that (27), (29), (30), (31), and (32) should all be defective. In the absence of non-dynamic alternatives capable of yielding similar results, these are powerful considerations in favor of the general direction Groenendijk et al. (1996) explore. (Aloni 2001 is also rich with insight into problems closely related to the ones discussed here.)

The dynamic system I will set out below owes much to Groenendijk et al.'s (1996) approach, and overlaps with it in key respects. My central interest is not in attempting to improve upon its empirical coverage, but rather in trying to isolate a relatively minimal dynamic semantics that is adequate to the puzzles outlined above. Groenendijk et al. (1996) are after a unified theory of epistemic 
modality de dicto and de re, donkey anaphora, intersentential anaphora, modal subordination, and more besides. The resulting theory has many moving parts, and it is not completely transparent which parts of the machinery are motivated by facts about de re epistemic modal discourse per se. My aim is to get clearer on the question to what extent the facts about epistemic modality de re, considered in isolation from problems that are traditional to dynamic semantics such as donkey anaphora or presupposition projection, might nevertheless themselves motivate a dynamic approach to meaning; and further, I would like to get clearer on exactly what tools from the dynamic semantics tradition are called for. In short, I am seeking the minimum effective dose of dynamic medicine sufficient for addressing the maladies we have reviewed.

In this connection, a central point I hope to bring out with the semantics below is the following:

The various puzzles about epistemic modality de re we have seen can be solved without any appeal to the notion of a discourse referent.

By 'discourse referent', I of course have in mind the notion introduced by Karttunen (1969) and centrally employed in the leading dynamic semantics frameworks since the earliest work in this tradition. Many theorists familiar with dynamic semantics think of it as deeply intertwined with the idea of taking the concept of a discourse referent seriously from a semantic point of view. But we should not conflate the question of discourse referents with the general question whether the compositional semantics for some fragment of language should take a dynamic form. These debates are linked, but they are distinct. It may be that the facts about epistemic modal discourse are best modeled within some dynamic semantic formalism. Even if so, it needn't follow that the dynamic formalism in question must involve the notion of a discourse referent. The dynamic semantics given below does not.

The formalization and management of discourse referents is the source of most of the complexity in the system of Groenendijk et al. (1996). We can give a discourse referent-free-but still dynamic-treatment of quantification that avoids these complexities while still addressing the puzzles above. Of course, discourse referents may yet be needed to deal with other problems, like intersentential and donkey anaphora, or modal subordination. I am not objecting to the system of Groenendijk et al. (1996), which is partly directed at addressing these problems. Again, the point here is to attempt to isolate and clarify what semantic tools are required, or motivated by, what linguistic phenomena.

We will present the semantics as a semantics for a simple formal language, one intended to model the relevant aspects of the fragment of natural language which is our focus. Our formal language is, in essence, just the language of quan- 
tified modal logic. Assume a stock of variables $\left\{x_{1}, x_{2} \ldots\right\}$, and for every $m \in \mathrm{N}$, a set $\left\{F_{1}^{m}, F_{2}^{m}, \ldots\right\}$ of $m$-place predicates. Well-formed formulas $\phi$ are defined by the following grammar:

$$
\phi::=F_{i}^{k}\left(x_{1}, \ldots, x_{k}\right)|\neg \phi|(\phi \wedge \phi)|\diamond \phi| \exists x(\phi, \phi) \mid \forall x(\phi, \phi)
$$

We assume the quantifiers are dyadic, to better approximate the corresponding natural language expressions. To leave conceptual room for the possibility of failures of duality of the sort reviewed in the last section, we explicitly add both quantifiers to the language separately. We define $\square \phi:=\neg \diamond \neg \phi$. We let $\perp:=(\phi \wedge$ $\neg \phi)$ for some well-formed $\phi$.

To give the dynamic semantics, we need to state what our models are, define what information states are (the objects that sentences will serve to update), and define the notion of a variable assignment. A model $\mathcal{M}$ is a triple $\langle W, D, V\rangle$ where $W$ is a non-empty set of possible worlds, $D$ is a domain of possible individuals, $V$ is a valuation function taking a predicate $F_{i}^{k}$ and world $w \in W$ to a (possibly empty) set of $k$-tuples of objects from $D$. An information state is a set of possible worlds (a subset of $W$ ). A variable assignment $g$ maps each variable $x_{i}$ to some $g\left(x_{i}\right) \in D$. We adopt the standard definition of a modified variable assignment: for $d \in D$, let $g\left[x_{i} / d\right]$ be the assignment such that $g\left[x_{i} / d\right]\left(x_{i}\right)=d$, and which is otherwise everywhere like $g$.

Our treatment of the semantics of variables will not be particularly dynamic in character. It will be more like the treatment found in ordinary first-order logic. This is the respect in which the present account most differs from typical treatments of quantification in a dynamic setting. In contrast to the most familiar dynamic approaches to quantification (e.g., Heim 1982; Groenendijk \& Stokhof 1991b; Groenendijk et al. 1996), we will not be postulating a special domain of discourse referents that gets dynamically updated in the process of interpretation, and which is centrally employed in the interpretation of variables. We do not exclude the possibility that the present account could be extended in such a direction, but this kind of extension proves to be unnecessary for addressing the problems which are our main concern.

Now the meaning of any sentence is a function which maps an information state to an updated information state (relative to a variable assignment). The semantics will take the form of a recursive definition of the update of any information state $s$ on any wff $\phi$ relative to any assignment function $g, s[\phi]^{g}$. We will state the whole semantics at once, and then discuss each clause one by one. Here is the semantics: 


$$
\begin{aligned}
& s\left[F_{i}^{k}\left(x_{1}, \ldots, x_{k}\right)\right]^{g}=\left\{w \in s:\left\langle g\left(x_{1}\right), \ldots, g\left(x_{k}\right)\right\rangle \in V\left(F_{i}^{k}, w\right)\right\} \\
& s[\neg \phi]^{g}=s-s[\phi]^{g} \\
& s[(\phi \wedge \psi)]^{g}=s[\phi]^{g}[\psi]^{g} \\
& s[\diamond \phi]^{g}=\left\{w \in s: s[\phi]^{g} \neq \varnothing\right\} \\
& s\left[(\phi \rightarrow \psi]^{g}=s-\left(s[\phi]^{g}-s[\phi]^{g}[\psi]^{g}\right)\right. \\
& s\left[\exists x_{i}(\phi, \psi)\right]^{g}=\bigcup_{d \in D} s[\phi \wedge \psi]^{g\left[x_{i} / d\right]} \\
& s\left[\forall x_{i}(\phi, \psi)\right]^{g}=\bigcap_{d \in D} s[\phi \rightarrow \psi]^{g\left[x_{i} / d\right]}
\end{aligned}
$$

I will abstract from the relativity of semantic values to variable assignments below wherever it is harmless and convenient. We define consequence in terms of incorporation in an information state rather than in terms of truth at a point of evaluation, and we define a notion of coherence :

s incorporates $\phi$ relative to $g$ just in case $s[\phi]^{g}=s$.

A wff $\psi$ is a consequence of a set $\Gamma$ of wffs, $\Gamma \vDash \psi$, relative to $g$ iff for all information states $s$, if $s$ incorporates each $\phi \in \Gamma$ relative to $g$, then $s$ incorporates $\psi$ relative to $g$.

$\phi$ is coherent just in case for some $g$ and some nonempty $s, s[\phi]^{g}=s$.

We can get a sense of each semantic clause by observing how the corresponding update might serve to update the common ground of a conversation (construing the latter broadly along the lines of Stalnaker 1978; 2002). Think of a conversation as determining a mutually shared body of information, and think of declarative speech acts as having the conventionally understood role of updating this mutually shared body information, usually (but not always) by adding information to it. The common ground determines a set of open possibilities - an information state-namely, the possibilities not excluded by what is mutually taken for granted. We can, for starters, model the common ground as this set of possibilities. Following Stalnaker, I will call this set the context set. Adding information, from the point of view of this model, is a matter of eliminating possibilities.

To further fix ideas, it helps to assume that a conversational context also determines a variable assignment (Kaplan 1989: 591). We can model pronouns, for instance, as variables, and deictic uses of pronouns as cases where the values of the relevant variables are fixed by the contextually supplied variable assignment. Our ultimate treatment of quantification does not strictly require this analysis of deictic pronouns, or the assumption that a conversation context determines a variable assignment; but these will emerge as natural and convenient assumptions to make in the present setting. 
Now let us consider each clause above, beginning with the atomic case. This case reflects the most ordinary sort of assertion. Here update can be thought of as proposition-adding, with "proposition-adding" modeled along the lines of Stalnaker (1978): propositions are modeled as sets of possible worlds, and adding a proposition to the context set is just eliminating the possibilities incompatible with it. Update is in effect a matter of intersecting the common ground with a possible worlds proposition. For example, if the sentence whose semantics we are modeling is 'She is a doctor', this sentence will update the input context set $s$ by knocking out the worlds $w$ in $s$ where the referent assigned to the pronoun by the contextually determined variable assignment does not fall into the extension of the predicate 'is a doctor' relative to $w$. The result will be a context set that incorporates the information that the referent in question is a doctor.

The semantics for negation goes back at least to Heim (1983). The change to the context set induced by 'She isn't a doctor' is calculated by first updating the context set with 'She is a doctor', yielding the subset of context set worlds where the referent in question is a doctor, and then "subtracting" this set from the original context set-that is, by taking the complement of this set relative to the original context set. The context set that results is the subset of the original context set wherein the referent in question is not a doctor - the intuitively correct result.

The semantics for conjunction goes back at least to Heim (1982), which was in turn inspired by Stalnaker (1974). Groenendijk et al. (1996) also adopt this clause. In the unembedded case, a conjunction is equivalent in its dynamic effect to consecutive assertions of the conjuncts.

The semantic clause for the epistemic possibility modal is due to Veltman (1996), with the basic underlying idea occurring already in Stalnaker (1970) and Veltman $(1984 ; 1985)$. (Stalnaker put it like this: “'It may be that $P^{\prime} \ldots$ may be interpreted as making explicit that the negation of $P$ is not presupposed in the context," Stalnaker 1970: 286-7.) The idea has since appeared in much subsequent work on epistemic modality in the dynamic tradition (for example, Landman 1990; Groenendijk \& Stokhof 1991a; van Benthem 1996; Groenendijk et al. 1996; Aloni 2001; Beaver 2001; Gillies 2004; Asher \& McCready 2007; Willer 2010; 2013; Yalcin 2012b). It is perhaps easiest to appreciate the idea from the point of view of $\diamond \phi$ 's "incorporation conditions". The basic thought is that an information state $s$ incorporates $\diamond F x$ (relative to $g$ ) just in case $s$ is coherently updatable with the prejacent $F x$-which is to say, just in case there is a world $w$ in $s$ where $F x$ is true (i.e., where $g(x)$ is in the extension of $F$ relative to $w$ ). An information state incorporates 'She might be a doctor', for instance, just in case the information state leaves open a possibility wherein the relevant referent is a doctor. This is an intuitively natural idea: an information state is a set of possibilities, and these possibilities just are what might be the case according to that state. The Veltman- 
style semantic clause is usually described as a "test" semantics: the update corresponding to $\diamond \phi$ "tests" the input information state for coherent updatability with $\phi$. If the state passes, the output state is just the input state itself; otherwise the state "fails" and the output context is the empty set. In essence, the update associated with $\diamond \phi$ effects a binary distinction within the space of information states, separating the states that are coherently updatable with $\phi$ from those that aren't. ${ }^{13}$ You can think of the test associated with $\diamond \phi$ as keying into a "global" property of an information state-the property of being coherently updatable with $\phi$. We cannot in general construe the update associated with $\diamond \phi$ as ordinary proposition-adding: there is no stable condition on possible worlds associated with $\diamond \phi$, such that update consists in intersecting this proposition with the input information state. ${ }^{14}$

The clause for $\rightarrow$ corresponds to the analysis of indicative conditionals given by Heim (1983). As it renders $(\phi \rightarrow \psi)$ dynamically equivalent to $\neg(\phi \wedge \neg \psi)$, this is a sort of dynamic material conditional analysis. Intuitively speaking, the clause says the following: to update a state of information with $(\phi \rightarrow \psi)$, eliminate the worlds which would survive update with $[\phi]$, but would not survive update with $[\phi][\psi]$. Restricting attention to the case where $\phi$ and $\psi$ are ordinary factual claims, the idea in essence is that $(\phi \rightarrow \psi)$ updates an information state by eliminating those worlds in the state where $\phi$ but not $\psi$ holds (cf. Stalnaker 1975). That is a natural idea about the conversational dynamics of indicative conditionals. I will return to the question to what extent $\rightarrow$ tracks the indicative conditional below (Section 11).

Finally we come to the clauses for the quantifiers. These are inspired by the familiar idea that an existentially quantified statement can be intuitively understood as roughly equivalent to a (perhaps infinitary) disjunction, and that a universally quantified statement can be intuitively understood as roughly equivalent to a (perhaps infinitary) conjunction. (A substitutional version of the clause for the existential quantifier presented here was first suggested to me by Simon Goldstein, personal communication, October 11, 2014; I am indebted to him for discussion.) This analysis is quite similar to the existential quantifier of

13. It is natural to worry, as a number of authors have (Yablo 2011; Yalcin 2011; Willer 2013) about the fact that unembedded epistemic possibility sentences do not (as a matter of their seman-

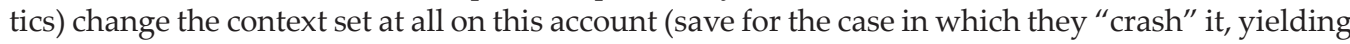
the empty state). Various extensions of Veltman's semantics are possible that address this concern: see for example Asher and McCready (2007), Willer (2010; 2013), Yalcin (2011; 2012b). See also Moss (2015) for relevant discussion. The solutions offered by Willer (2010; 2013) and (following Willer) Yalcin (2012b) can be applied to the semantic framework developed here.

14. This last point is part of the motivation for the expressivist interpretation of epistemic discourse recommended in Yalcin (2011; 2012a). See Rothschild and Yalcin (in press) for more on the sense in which Veltman's update semantics for $\diamond \phi$ can and cannot be understood on the model of intersective propositional update. 
Groenendijk et al. (1996), save for the important difference that on their account, existential quantifiers introduce discourse referents. To update an information state $s$ with 'Somebody quarantined is infected', for instance-formalize this as $\exists x(Q x, I x)$ - we union the various results of updating $s$ with $[Q x \wedge I x]^{g[x / d]}$, which is to say, with $[Q x]^{g[x / d]}[I x]^{g[x / d]}$, for all $d \in D$. Any $w \in s$ where there exists no one who is both infected and quarantined will end up eliminated on this semantics, for no such world can survive update with $[Q x]^{g[x / d]}[I x]^{g[x / d]}$, no matter what $d$ is. That is the desired result. Note also that this semantics does not entail that $s[\exists x(Q x, I x)]^{g}$ incorporates any "singular information", to the effect that some particular object is both quarantined and infected. The generality of existential quantification is preserved.

The semantic clause for the universal quantifier is like that of the existential quantifier, save that intersection replaces union, and the conditional connective replaces the conjunction symbol. The idea of formalizing ordinary language universal quantified claims by resort to a tacit material implication will be a familiar idea to anyone who has taken an introductory logic course, and the present approach is a sort of dynamic counterpart to this kind of analysis. To update an information state $s$ with 'Everyone quarantined is infected', for instance- formalize this as $\forall x(Q x, I x)$ - we intersect the various results of updating $s$ with $[Q x$ $\rightarrow I x]^{g[x / d]}$, for all $d \in D$. This has the effect of eliminating from $s$ any world that contains a quarantined but uninfected person.

\section{Problems Overcome}

It is a familiar point that the Veltman-style dynamic analysis of epistemic modals, together with the standard dynamic analysis of conjunction as akin to consecutive assertion, predicts the infelicity of unembedded, closed epistemic contradictions like:

(41) \# John isn't infected and he might be infected. $(\neg \phi \wedge \diamond \phi)$

The explanation is that the update function semantically associated with this sentence returns the empty set ("crashes the context"), no matter what the input state is. Once the first conjunct eliminates the worlds where John is infected from the context set, the resulting context set is guaranteed to "fail" the test expressed by the second conjunct. Generally speaking, any composite update of the form $[\neg \phi][\diamond \phi]$ will map any information state to the empty set.

Now returning to one of our key problem sentences (repeated): 
(27) \# Some person who is not infected (is a person who) might be infected. $\exists x(\neg I x, \diamond I x)$

It is not far off to say that the explanation of the infelicity of (27) we can give using the semantics presented in the previous section piggybacks on the explanation just given of the infelicity of sentences like (44). By the definitions, the update associated with (27) on an information state $s$ is made by unioning the various results of updating $s$ with the composite updates of the form $[\neg I x][\diamond I x]$, for each possible assignment of values to $x$. But as just noted, $[\neg \phi][\diamond \phi]$ maps any information state to the empty set. Since the union of a collection of empty sets is of course the empty set, the update [(27)] will always return the empty set-it will crash any context set.

Let me try to say something intuitive about how this solution works. Almost everyone likes to think of epistemic possibility modals as serving to express existential quantification over some set of worlds. Much of the debate about these modals concerns how this set of worlds is fixed. In the dynamic setting, we can think of the relevant set of worlds as given by the context (state of information) that the modal sentence serves to update. The advantage of the dynamic formulation is that the relevant context can easily be a local context-a state of information provisionally calculated in the compositional semantics for fixing the semantic value of the whole. The compositional semantic contribution of $\diamond I x$ in $\exists x(\neg I x, \diamond I x)$ is a function of how it is apt to update a local context (information state) already incorporating the information that $\neg I x$ - where the update associated with the latter is something that itself varies with the value of the variable. In the big picture, what the dynamic formulation gives us is an elegant way to model epistemic modals as exquisitely sensitive to intrasentential informational dynamics - a sensitivity they appear to have, given the problems reviewed above. ${ }^{15}$

15. The semantics also explains the defect in (repeated):

(30) \# Every person who is not infected (is a person who) might be infected.

(31) \# Every person who is not infected and might be infected is quarantined.

From a semantic point of view, these are relevantly analogous to the following problematic modalfree sentences:

(42) \# Every person who is not infected is infected.

(43) \# Every person who is not infected and is infected is quarantined.

On the textbook predicate logic semantics for the universal quantifier, (42) is logically equivalent to the claim that everyone is infected, and (43) is rendered vacuously true. On the current dynamic semantics for the universal quantifier, these results remain in place, and they extend to (30) and (31): (30) is predicted to be equivalent to the claim that every person is infected, and (31) is predicted to be vacuously true. (With the dynamic counterpart of "vacuous truth" being "incorporation 
We do face a question, however, about exactly how dynamic the analysis should be. Returning to:

(28) ?? Some person who might be infected is not infected.

As noted, many speakers find this odd, though the judgments appear to be less robust as compared with (27). From the point of view of the semantics stated above, (28) is importantly different from (27). (27) will crash any context, but not so (28). These sentences are not equivalent on our semantics (yet). By the definitions, the update associated with (28) on an information state $s$ is made by unioning the various results of updating $s$ with the composite updates of the form $[\diamond I x][\neg I x]$, for each possible assignment of values to $x$. Unlike composite updates of the form $[\neg \phi][\diamond \phi]$, however, the composite update $[\diamond \phi][\neg \phi]$ does not map arbitrary information states to the empty set. If one starts out with an information state $s$ including a mix of $\phi$ and $\neg \phi$ worlds, then $s[\diamond \phi][\neg \phi]$ will be the (nonempty) subset of $\neg \phi$ worlds in $s$. Order can matter: commutativity is not a general property of updates. As a result, the semantics as stated does not license the following equivalence in general:

$$
\exists x(\phi, \psi) \Leftrightarrow \exists x(\psi, \phi)
$$

Moreover, (28) is coherent in the technical sense defined above: there are nonempty states of information incorporating it (i.e., it has nonempty fixed points). ${ }^{16}$

Although the restrictor clause of an existential quantifier cannot be freely swapped with its nuclear scope, we do have duality on the present semantics: $\exists x(\phi, \psi)$ entails $\neg \forall x(\phi, \neg \psi)$, and $\forall x(\phi, \psi)$ entails $\neg \exists x(\phi, \neg \psi)$. (See the appendix.) So, considering again:

by every information state".) Pretty much any story we were prepared to tell about the defect in sentences like (43) and (42) in the setting of the classical semantics for the quantifiers can be carried over to the present dynamic setting, and extended to (30) and (31). One standard line of explanation appeals to the idea that any universally quantified sentence of the relevant kind presupposes that there exists something which satisfies its restrictor clause. If we assume this, then we have an explanation for why (42) and (43) strike us as odd: (43) has a contradictory presupposition, and (42) has a presupposition which is incompatible with its own content. These forms of explanation will extend straightforwardly to (30) and (31), respectively.

16. In this respect (28) is importantly unlike:

(44) \# John might be infected and he isn't.

As Groenendijk et al. (1996) note, sentences of this form are not coherent-there is no stable nonabsurd body of information that incorporates this conjunction. That is adequate for explaining the defect in (44). This kind of explanation cannot extend to (28), as noted for similar examples by Aloni (2001). (See the appendix for further discussion.) 
(33) Not everyone who might be infected is infected.

The semantics has the result that (33) is equivalent to (28) but not (27).

The result that (33) is not equivalent to, and does not entail, (27) is a good one. But what about the result that (28) is equivalent to (33)? This result is more questionable; as already noted, there does seem to be a difference in markedness between $\neg \forall x(\diamond \phi, \phi)$ and $\exists x(\diamond \phi, \neg \phi)$. The order-sensitivity permitted in the semantics as stated may be out of proportion with the empirical facts (cf. Aloni 2001). In particular, we may prefer for our semantics to render [(27)] and [(28)] as equivalent, with both being destroyers of information states. To get such a result, we need to add to or modify the semantics above. I bracket the question how exactly to deal with (28) and its kin for now, returning to it in the next section.

Meanwhile, we can observe that the present semantics succeeds in blocking the problematic entailment from sentences like (34) and (35) (repeated) to sentences like (27) and (29) (repeated):

(34) Every person quarantined is a person who might be infected.

(35) Some person quarantined is not infected.

(29) \# Some person who is not infected and might be infected is quarantined.

The reader can easily confirm that (34) and (35) can be jointly incorporated in a nonempty information state. As already observed, sentences like (27) and (29) are only incorporated by the empty information state. So the entailment does not go through.

Further, the present account predicts the sort of failure of Universal Modus Tollens highlighted above. Let $d \in D$ be the referent of constant $a,{ }^{17}$ and consider an information state $s$ such that (i) for some world $w \in s, d \notin V(G, w)$; (ii) at every world $w \in s, V(F, w) \subseteq V(G, w)$; and (iii) for some world $w \in s, d \in V(F, w)$. By (i) and the semantics, $s$ incorporates $\neg \square G a$ (which is equivalent to $\diamond \neg G a$ ). By (ii) and the semantics, $s$ incorporates $\forall x(F x, \square G x)$. But by (iii) and the semantics, $s$ does not incorporate $\neg F a$, for $s$ leaves open a world where $d$ does fall into the extension of $F$. Note further that if the boxes are removed, the inference does go through: $\forall x(F x, G x)$ and $\neg G a$ do jointly entail $\neg F a$, as the reader can confirm. This is the intuitively correct result.

One might worry that the semantics for every and some given above is not

17. Our language does not officially contain constants for individuals, but the extension is trivial and familiar. Add a stock of constants to the language. A term is any variable or constant. We add a denotation function which serves to interpret terms in atomic formulas. Where the term is a variable, the extension of the term is given by the variable assignment. Where the term is a constant, its extension is some particular object in $D$. I have this standard kind of extension in mind. 
stated in a generalized form suitable for arbitrary quantificational determiners, even though our basic problem plainly recurs for other determiners - for instance:

(45) \# Most of those who are not infected might be infected.

Building on Chierchia (1992; 1995), a generalized format for quantificational determiners suitable to the present context would be: ${ }^{18}$

$$
\begin{aligned}
s[Q(\phi, \psi)]^{g}= & \{w \in s: \\
& \left.\left\{d \in D: w \in s[\phi]^{g: x \rightarrow d}\right\} R_{Q}\left\{d \in D: w \in s[\phi]^{g: x \rightarrow d}[\psi]^{g: x \rightarrow d}\right\}\right\}
\end{aligned}
$$

where $R_{Q}$ is the second-order relation appropriate to the determiner $Q$. So for example, our clause for existential quantification could be re-written as:

$$
\begin{aligned}
s[\exists x(\phi, \psi)]^{g}= & \{w \in s: \\
& \left.\left\{d \in D: w \in s[\phi]^{g: x \rightarrow d}\right\} \cap\left\{d \in D: w \in S[\phi]^{g: x \rightarrow d}[\psi]^{g: x \rightarrow d}\right\} \neq \varnothing\right\}
\end{aligned}
$$

Most would be:

$$
\begin{aligned}
s\left[\operatorname{MOST} x(\phi, \psi)^{g}=\right. & \{w \in s: \\
& \frac{1}{2}\left|\left\{d \in D: w \in s[\phi]^{g: x \rightarrow d}\right\}\right| \\
& \left.<\left|\left\{d \in D: w \in s[\phi]^{g: x \rightarrow d}[\psi]^{g: x \rightarrow d}\right\}\right|\right\}
\end{aligned}
$$

And so on. This would extend the basic solution available in the present semantics to (45) and to other quantificational determiners. ${ }^{19}$

\section{Idempotence and Consecutive Update}

Return now to the question what to say about (28) - or in general, about sentences of the form $\exists x(\diamond \phi, \neg \phi)$. Some theorists-especially those already of the dynamic persuasion - may already be satisfied with a semantics of the sort given, wherein the order-sensitivity of dynamic update predicts a real difference between (27) and (28). But it seems that speaker judgments leave it less than ob-

18. I am indebted here to Daniel Rothschild for discussion.

19. One might ask whether the decision to take $\left\{d \in D: w \in s[\phi]^{\mathrm{g}: \mathrm{x} \rightarrow \mathrm{d}}[\psi]^{\mathrm{g}: \mathrm{x} \rightarrow \mathrm{d}}\right\}$ rather than simply $\left\{d \in D: w \in s[\psi]^{\mathrm{g}: x \rightarrow \mathrm{d}}\right\}$ to be the second relatum for $R_{Q}$ could be motivated in abstraction from the puzzles being explained here. For some relevant discussion, see Rothschild (2011). 
vious whether this order-sensitivity is in fact desirable. ${ }^{20}$ Again, many subjects do find sentences like (28) considerably less felicitous than garden-variety de re sentences (such as 'Someone who might be infected is quarantined'). Second, even those who find (28) felicitous often judge the following sentences to be more problematic:

(46) \# Some person who might be infected and isn't infected is quarantined.

(47) \# Everyone who might be infected and isn't infected is quarantined.

Here the $\diamond \phi$ and $\neg \phi$ sentences are in the dynamically kosher order, but they are coordinated in the same clause. For some reason, their being in same clause seems to render the corresponding sentences (more) defective, at least for many speakers.

The empirical situation thus appears to be more nuanced than a flatfooted dynamic approach might lead us to expect. With judgments potentially becoming more fine-grained and subtle here, detailed further work should perhaps rest on empirical studies that clarify the judgment data to be explained. The remarks in this section are accordingly more speculative. We could frame it as addressing a hypothetical question. Suppose that we wanted to grant that sentences like (28), (46), and (47) are not fine in semantic respects, that there is something semantically deviant about them. Suppose we wanted a theory predicting them to be marked. What theory might we give, taking the semantics supplied above as a starting point? ${ }^{21}$

We can begin with the point that the semantics as stated does predict that (28) has a curious property. Suppose for instance that we are in a context (information state) $s$ where it is presupposed that Jane, and only Jane, might be infected

20. Theorists in the dynamic tradition have often suggested that it is a datum that (unembedded) discourses of the form $\diamond \phi, \neg \phi$ are much more felicitous than the reverse discourse $\neg \phi, \diamond \phi$ (Groenendijk \& Stokhof 1991a; Veltman 1996; Groenendijk et al. 1996; Beaver 2001). Groenendijk and Stokhof (1991a), for instance, suggest that there is a "marked contrast" (58) in acceptability between the following two discourses:

It might be raining ... It isn't raining.

It isn't raining ... It might be raining.

Many speakers judge these discourses to be equally bad, however. Further, what asymmetry there is in acceptability between them would not be difficult to predict within a non-dynamic but context-sensitive semantics for epistemic modals, such as the account developed in Kratzer (2012). Reflection on discourses such as these thus provides very little support per se for the Veltman-style dynamic semantic approach to epistemic modals. A stronger case in favor of Veltman's approach over Kratzer's is the difficulty that the latter but not the former approach has in the face of the puzzles about epistemic modality de re reviewed above.

21. See Aloni (2001) for one important alternative to the answer to this question I explore here. 
(so that if a world in $s$ contains an infected individual, that individual is identical to Jane), and where it is not presupposed that she is infected (so that there are worlds in $s$ where Jane is not infected). An update of this context with (28) will result in a context $s^{\prime}$ which entails that no one is infected. What is curious here is that this output $s^{\prime}$ does not actually incorporate (28) itself. Whereas $s[(28)]=$ $s^{\prime}$, it is not the case that $s^{\prime}[(28)]=s^{\prime}$; on the contrary, $s^{\prime}[(28)]=\emptyset .{ }^{22}$ Applied to $s$, the sentence seems to destroy its own presupposition: it updates the context by turning it into a context which is inhospitable for its own update. Extending the terminology of Hintikka (1962) somewhat, we might call (28) anti-performative relative to $s^{23}$

This is an unusual result. What this highlights is that the update semantically associated with (28) by the semantics above is not generally idempotent (where an update $[\phi]$ is idempotent just in case for all information states $s, s[\phi][\phi]=s[\phi])$. In a similar way, the reader can confirm that all of the following sentences express update functions that fail to be idempotent:

(48) ?? It might be raining and it isn't raining.

(49) ?? If Jane might be infected, then she isn't infected.

(50) ?? Everybody who might be infected is not infected.

Many speakers judge these sentences to be at least a bit odd, if not very odd. ${ }^{24}$

A suggestion presenting itself in the face of these data is the idea that there is a certain norm of assertion that all of these sentences violate. We could call it the idempotence norm :

Idempotence norm. The conversational update semantically associated with any assertion must be idempotent.

22. That is, supposing that $s^{\prime}[(28)]$ is even defined. If we adopt the view that determiners generally presuppose that their restrictors are non-empty, then (28)'s presupposition will not be satisfied in $s^{\prime}$. We may ultimately wish to model this as the undefinedness of [(28)] at $s^{\prime}$.

23. Discussing an analogous example, Hintikka writes, "these words have a curious effect which may perhaps be called anti-performatory. You may come to know that what I say was true, but saying it in so many words has the effect of making what is being said false" (1962: 90-1). (I am indebted here to discussion with Wesley Holliday.)

24. Of course, one could rig up contexts for each of these sentences which would improve the way that they ring. Suppose, for instance, that half the people in a waiting room are awaiting the test results for a certain disease that they each might have. A nurse might suddenly appear and say: "Good news: everybody here who might be infected is not infected!" We would of course understand what she is getting at. Nevertheless, many speakers find this way of talking comparatively marked, and less felicitous or natural than "Everybody here who might have been infected is actually not infected", or simply "No one here is infected". 
The idea that there is an idempotence norm seems natural. It is commonly thought that, in normal conversations where the aim is to transfer information, we aim to say what we believe or know. From a dynamic perspective, believing or knowing what a sentence $\phi$ says is most naturally modeled as being in a nonempty state of information that incorporates $[\phi]$ (Heim 1992). It is accordingly natural to expect conversational updates to be such as to take any conversation to a fixed point of that update. Idempotent updates do exactly that. The fixed points of $[\phi]$ would intuitively correspond to the property of one's state of belief or knowledge that one is attempting to coordinate one's interlocutors upon in conversation in asserting $\phi$.

The trouble with the idempotence norm is that it seems too strong. If we are correct that there is a nontrivial difference in markedness between (28) and (33) (repeated):

(33) Not everyone who might be infected is infected.

then the idempotence norm would not explain the difference. Further, it would incorrectly predict (33) to be infelicitous. As already noted, our semantics renders (33) and (28) equivalent; thus (33), too, fails to be idempotent.

The sentences (33) and (28) differ only in their compositional semantics. If there is a difference in acceptability between them, a natural hypothesis is that this owes to a constraint that applies at the compositional semantic level. The idempotence norm, being a pragmatic norm of assertion, is not such a constraint.

Partly in response to the puzzles of epistemic modality de re discussed in this paper, Klinedinst and Rothschild have conjectured that there might be a kind of idempotence requirement that applies at the compositional semantic level. ${ }^{25}$ Here is an example, very roughly stated, of the kind of constraint that could do the job in the present context:

Consecutive update idempotence. For any sentence $\phi$ with sentential constituents $\psi$ and $\gamma$, if $[\phi]$ is defined anywhere in part in terms of the composite update function $[\psi][\gamma]$, that composite update function must be idempotent. ${ }^{26}$

25. Reporting joint work with Klinedinst, Rothschild suggested the possibility of a constraint along these lines in a lecture to the Meaning Sciences Club at Berkeley on April 28, 2014; their manuscript in progress on this topic is Klinedinst and Rothschild (2015) (which in turn draws upon this paper). I am greatly indebted to their insights. The specific semantic constraint I consider here is not proposed by them, but it is inspired by their suggestions.

26. When I talk about how $[\phi]$ is "defined", I of course mean its canonical decomposition in accord with the recursive semantics above. 
The sentence (28) fails the consecutive update idempotence requirement because $[(28)]$ is defined on arbitrary information state $s$ in terms of how $s$ would be updated by composite updates of the form $[\diamond \phi][\neg \phi]$. But such composite updates, we know, are not idempotent: $s[\diamond \phi][\neg \phi]$ may well be nonempty, whereas $s[\diamond \phi]$ $[\neg \phi][\diamond \phi][\neg \phi]$ must be the empty set. In contrast, (33) nowhere requires in its semantics the appearance of a nonidempotent composite update. It is defined in terms of composite update functions of the form $[\diamond \phi][\phi]$, but such update functions are idempotent. Thus (28) but not (33) violates the consecutive update idempotence requirement. A constraint like this would predict localized failures of duality for pairs like (28)/(33), and would restore the equivalence of $\exists x(\phi, \psi)$ and $\exists x(\psi, \phi)$.

We could view this requirement as something we simply superadd to the semantics as it is stated; or we could build it into the semantics. The latter could be achieved in various ways. One possible direction would be the following. For any update function $[\psi]$, we can define a new function $[\psi]^{*}$. The new function takes an update function as an argument and returns a new update function, as follows: 27

$$
s[\phi][\psi]^{*}=\left\{\begin{array}{l}
(s[\phi])[\psi] \text { if }(s[\phi])[\psi] \text { incorporates both }[\phi] \text { and }[\psi] \\
\varnothing \text { otherwise }
\end{array}\right.
$$

In $s[\phi][\psi]^{*}$, we are to understand that the argument of $[\psi]^{*}$ is $[\phi]$ (not $s[\phi]$ ); the output of $[\psi]^{*}$ on $[\phi]$ is a new update function that acts on information states $s$. In a sense, $*$ lifts an update function on information states to an update on update functions. It maps $[\phi]$ to a new update function, defined in terms of $[\phi]$ and $[\psi]$. The new update function is equivalent to the composite update function $[\phi][\psi]$ just in case that composite update maps into a fixed point of both $[\phi]$ and $[\psi]$; otherwise the result is absurdity.

Then the adjustment to the semantics required is just a matter of sprinkling asterisks: anywhere the compositional semantics defines the update of a complex expression in terms of a consecutive update $[\phi][\psi]$ (as, for example, in the clauses for $\wedge$ and $\rightarrow$ ), we replace this with $[\phi][\psi]^{*}$. Alternatively and more generally, we could reinterpret our notation, stipulating that $[\phi][\psi]$ always just means $[\phi][\psi]^{*}$. (We would recover the previous understanding of consecutive update with explicit parentheses: $(s[\phi])[\psi]$.) This would be one way to capture what we are after in the consecutive update idempotence requirement.

27. In place of " $\emptyset$ otherwise", another option would be "else undefined". These choices come apart on, for example, $\neg(\neg \phi \wedge \diamond \phi)$; on the first choice this will be a tautology (more precisely: incorporated by any information state); on the second, undefined. I opt to render this sentence true, but I hardly see this as a decisive consideration. 
On the one hand, this adjustment to the semantics is a step back from dynamicness, as it serves to remove order-sensitivity from the system, and ordersensitivity is a canonical motivation for dynamic semantics. On the other hand, the analysis just described achieves a new extreme of dynamicness, for now sentences can update, not just information states, but also update functions themselves. Let me call the update on update functions $[\phi]^{*}$ associated with $[\phi]$ the superdynamic lift of $[\phi]$. I will call the view just described the superdynamic view of consecutive update.

Adopting this view of consecutive update, the sentences (27) and (28) are predicted to be equally marked. However, an intermediate position may be possible. One could explore the possibility of combining the normal understanding of consecutive update and the superdynamic view just described within a nondeterministic conception of the semantics. On this view, (28) could be semantically associated with both parses. We could postulate a general or "soft" preference for the superdynamic parse, holding that subjects only reach for the alternative parse when the superdynamic parse would lead to a crash (or is undefined, as on the variation considered in footnote 27). Perhaps such a view, suitably refined, could assist in accommodating the extent to which some speakers find (28) less marked than (27).

If something like the consecutive update idempotence requirement is correct, it is very natural to wonder why exactly it is correct. It seems easy enough to imagine functional systems of linguistic communication that would involve violations of this requirement, so the presence of this constraint cries out for further explanation. Perhaps the kinds of considerations mentioned in connection with the pragmatic idempotence norm above are part of the story. But this is just speculation. My aim has only been to identify a constraint that would unify what defect there might be in sentences like (28). If it is plausible that the constraint, or one like it, does unify the data, then inquiry into the ground of the constraint would be motivated. The preceding can be interpreted as a preliminary step in motivating such an inquiry.

I will close this section with a further item of speculation. In the context of generalized quantifier theory, it is widely thought that a universal feature of natural language determiners is that they express relations between properties (sets of individuals) satisfying conservativity, where

A second-order relation $R$ is conservative iff: $R(A, B)$ iff $R(A, A \cap B)$

Conservativity is described by von Fintel and Matthewson (2008) as "among the most celebrated semantic universals" in natural language semantics (160). (Note that conservativity is in a sense hard-wired into the semantics for generalized quantifiers given above.) 
In connection with every and some, the validity of the constraint is illustrated by intuitive equivalences like:

Every man smokes $\equiv$ Every man is a man who smokes

Some man smokes $\equiv$ Some man is a man who smokes

Now the observation I want to make is that the consecutive update idempotence constraint has a certain affinity with the conservativity property. Roughly and intuitively, the idea in both cases is that when we semantically evaluate the nuclear scope of the quantificational determiner, we want to keep the constraint already put in place by the restrictor clause. Conservativity captures this idea when the first-order properties related by the determiner's meaning are both persistent. But it seems we may want something more general-something which covers the situation with sentences like (27) and (28), where one of these first-order properties is not persistent. Here conservativity alone seems not to capture the judgments. Given a Veltman-style non-persistent semantics for epistemic modals, the complex predicates formed from these modals do not express the kind of well-behaved first-order properties we have in mind when we are thinking about conservativity. The consecutive update idempotence property might be thought of (inter alia) as a way of capturing the more general notion required.

It may be, then, that a deeper explanation of the consecutive update idempotence constraint is connected to whatever explains the conservativity property for determiners. At present, there is no widely accepted explanation for the conservativity constraint.

\section{Descriptions}

Let us turn back now to the facts about definite descriptions we began with:

(14) \# The winner is a person who possibly lost.

(15) \# The winner is a person who might not be the winner.

(16) \# The first person to contract the virus is a person who might not be the first to contract the virus.

As noted above, the two dominant views about definite descriptions in the literature trace back to Frege (1892) and to Russell (1905). In modern formulations, the Fregean view semantically associates definite descriptions with individual concepts - in particular, with partial functions from possible worlds or situa- 
tions to individuals (Thomason \& Stalnaker 1968; Thomason 1969; Barwise \& Perry 1983; Heim \& Kratzer 1998; Elbourne 2005; Elbourne 2013 is a comprehensive development). The Russellian view, by contrast, models the definite article as a quantificational determiner, and it correspondingly takes definite descriptions to be quantifiers. ${ }^{28}$

Standard construals of both views founder over examples like (14)-(16), for reasons already reviewed above. But there is a simple way to preserve a version of the Russellian view. That view may be taken as defining the definite article in terms of the universal and existential quantifiers. This gets us nowhere, of course, if we semantically analyze the universal and existential quantifiers along the usual predicate logic lines. But if the universal and existential quantifiers are instead given the dynamic semantics developed above, we get a dynamic version of the Russellian view that can predict the facts.

Let me illustrate. Consider first a sentence like:

(51) The winner is friendly.

Enriching our logical language with an $\iota$-operator representing the definite article, the Russellian can model this sentence as

$$
\iota x(W x, F x)
$$

(This formalization distorts the constituent structure of (51), but harmlessly for our purposes.) As is familiar, the Russellian holds that:

$$
\iota x(W x, F x) \equiv \exists x((W x \wedge \forall y(W y, x=y)), F x)
$$

(Keeping in place our dyadic syntax for the quantifiers, and adding an identity symbol to the language in the obvious way.) Now suppose we take this kind of equivalence to be definitional of the $\iota$-operator. In that case, any $\iota$-sentence can be viewed as shorthand for a corresponding quantificational sentence, and will thus have the same semantic interpretation as that quantificational sentence. Adopting this assumption, our question what goes wrong with, e.g.,

(15) \# The winner is a person who might not be the winner.

$$
\iota x(W x, \diamond \neg W x)
$$

reduces to the question what is wrong with:

28. Notable views not straightforwardly fitting into either of these paradigms include Heim (1982), Szabó (2000), Fara (2001). On the varieties of definite determiners, see Schwarz (2009), Rieppel (2013). 
(52) $\exists x((W x \wedge \forall y(W y, x=y)), \diamond \neg W x)$

Of course this manifestly entails, given our semantics,

$$
\exists x(W x, \diamond \neg W x)
$$

And we already know that this is doomed to crash any information state. Thus the present semantics predicts that (52) will crash any information state, and hence that (15) should be defective-the correct result. This dynamic Russellian view, then, solves the troubles about descriptions we have observed. (Of course, the dynamic departure required here from standard Russellian approaches is nevertheless substantial.)

Does the Fregean view also admit of some further elaboration that would enable it to predict the facts we have observed? Here there seems to be less room for maneuver. From a logical perspective, the textbook Fregean takes definite descriptions to be terms, and treats the definite article as an operator that forms terms from one-place predicates. The meaning of the definite article takes a oneplace first-order property and a possible situation $w$ to the unique individual possessing that property in $w$, if such there be. It is not easy to see how this kind of view can be reconciled with examples like (14)-(16). Consider (14). If, relative to each possibility $w$ left open by the common ground, the winner denotes the individual who is the winner in $w$, then (14) should be true at $w$ just in case that individual is not the winner in some other epistemically accessible possibility. As long as the individual concept the Fregean associates with the definite description has a variable extension across the epistemically accessible possibilitiesthat is, as long as the winner is not exactly the same individual relative to each epistemically accessible possibility — the sentence will admit of a true reading. That is the incorrect result.

Fregeans usually hold that a definite description comes with a existence presupposition, to the effect that there is something that satisfies the property corresponding to the description's restrictor. Fregeans usually also hold that definite descriptions come with a uniqueness presupposition, to the effect that just one object satisfies the description's restrictor. ${ }^{29}$ Neither of these presuppositions assists with the general problem. Let it be that (14) requires that any epistemically accessible world contain one and only one winner. The problem is as before.

Of course, this has hardly been a comprehensive study of descriptions. I have merely shown how to update one textbook view about descriptions in the face of

29. The Russellian position is often described as holding that sentences containing definite descriptions assert what, according to the Fregean view, is merely presupposed. This characterization of the view unfortunately obscures the possibility of a Russellian view on which uniqueness or existence are both asserted and presupposed. 
our difficulties. There are plainly other logically possible views of descriptions which could cover the data we have highlighted. I have said nothing to motivate the dynamic Russellian view sketched above as over these other rivals (and indeed, I have no inclination to defend that view in particular). An arguably simpler view, somewhat in the spirit of Szabó (2000), would hold that the semantic clause for definite descriptions is in effect that of the existential quantifier, and would locate the difference between definites and indefinites in their presuppositions. Whatever the further merits of such a view, it is plain that it too would avoid the difficulties presented here, and again by exploiting the above dynamic semantics for existential quantification. ${ }^{30}$

\section{Universal Quantification and Indicative Conditionals}

In this section I observe some subsidiary advantages of the present framework in connection with universal quantification and indicative conditionals.

To accept all of the preceding, one need not interpret $\rightarrow$ as the indicative conditional construction in natural language; one could take it as an artificial connective defined en route to theorizing about universal quantification. But there are considerations in favor of defining the indicative conditional with the help of $\rightarrow$. Let us use $\Rightarrow$ to represent the English indicative conditional construction. Consider the following pattern of inference:

Indicative via Universal (version 1 )

$\forall x(F x, G x)$

$\diamond F a$

$\therefore F a \Rightarrow G a$

Prima facie this pattern is valid. As an illustration:

(53) Every professor is friendly.

(54) Jane might be a professor.

So:

(55) If Jane is a professor, Jane is friendly.

30. And of course, the system presented here might be extended in some way with discourse referents. In that case, it is not hard to imagine an extension along the lines of Heim (1982), wherein

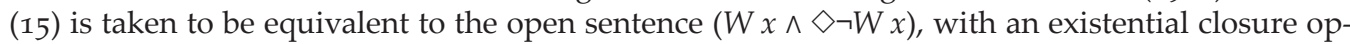
eration applying to the final interpretation of the sentence, and with definiteness associated with something like a familiarity presupposition. 
The conclusion seems unavoidable, given the premises. Further, there is in general a tension between affirming the universally quantified premise but rejecting a corresponding indicative conditional:

(56) All the professors are friendly. ?And if Jane is a professor, she's mean.

The conditional remark here makes it sound like the speaker is reconsidering the universally quantified claim she just made.

Should we make the stronger claim that (53) alone entails (55)-or more generally, that universally quantified sentences directly entail the corresponding indicative conditionals? On that question, consider an example like:

(57) Brenda is female. Every chief executive is male. ?So if Brenda is a chief executive, Brenda is male.

Here the indicative conditional conclusion seems intuitively not to follow; on the contrary, the intuition is instead that the conditional is in tension with the premises. The indicative seems to carry a presupposition whose truth is precluded by the information given by the premises, namely the presupposition that Brenda might be a chief executive. So accepting the premises creates no pressure to accept the indicative conditional conclusion. The pressure is only there when the antecedent of the indicative is taken to be epistemically possible.

One thing this suggests is that $\Rightarrow$ just is $\rightarrow$, except that the former carries a presupposition to the effect that the antecedent is epistemically possible. This idea about the presuppositions of indicative conditionals is of course familiar in the literature (Stalnaker 1975). Presupposition can of course be modeled in many ways. Following in the tradition of Heim (1983), let us represent this presupposition as a definedness condition on the corresponding dynamic update. We can define $\Rightarrow$ in terms of $\rightarrow$ as follows:

$$
s[\phi \Rightarrow \psi]:=[\phi \rightarrow \psi] \text { if } s[\diamond \phi] \neq \emptyset \text {; else undefined }
$$

Now it is easy to see that patterns in this general form:

$$
\begin{aligned}
& \forall x(F x, G x) \\
& \diamond F a \\
& \therefore F a \Rightarrow G a
\end{aligned}
$$

are valid in the system we have described. Given the way universal quantification is defined, it follows trivially that for any $s$, if $s$ incorporates $[\forall x(F x, G x)]$, 
then $s$ incorporates [ $F \alpha \rightarrow G \alpha$ ], for any constant $\alpha$; hence $s$ incorporates $[F a \rightarrow G a]$. If $s$ also incorporates $\diamond F a$, then by the semantic clause for $\Rightarrow$ above, it follows that $s$ incorporates $[F a \Rightarrow G a]$.

It should be noted that holding our semantics fixed, one can define an interesting entailment relation that does license the inference from $\forall x(F x, G x)$ to $F a \Rightarrow$ $G a$ directly, without the need for the ancillary premise $\diamond F a: 3^{1}$

$$
\begin{aligned}
& \text { Indicative via Universal (version 2) } \\
& \forall x(F x, G x) \\
& \therefore F a \Rightarrow G a
\end{aligned}
$$

The relevant notion is the notion von Fintel has called Strawson entailment (von Fintel 1999; 2001). This notion is close to our earlier notion of entailment, except that we quantify, not over all information states, but rather only over those that satisfy the presuppositions (if such there be) of all of the elements of the argument:

A wff $\psi$ is a Strawson entailment of a set of wffs $\Gamma$ just in case, for all information states $s$ such that for all $\phi \in \Gamma \cup\{\psi\}, s[\phi]$ is defined: if $s$ incorporates every element of $\Gamma, s$ incorporates $\psi$.

Since $F a \Rightarrow G a$ is only defined at information states $s$ such that $s[\diamond F a]=s$, we find that $\forall x(F x, G x)$ does Strawson-entail $F a \Rightarrow G a$. See von Fintel $(1999 ; 2001)$ on the broader empirical interest of this notion of entailment (also Starr 2014; Willer 2014)..$^{32}$

It is notable that Indicative via Universal (in either version) is not validated on more traditional approaches to quantifiers, modals and conditionals. For example, if we combine an ordinary extensional predicate logic semantics for universal quantification with a relational modal semantics for epistemic modals broadly in the spirit of Kratzer (2012), and added to this a Stalnaker-style semantics for the indicative conditional (Stalnaker 1975), the resulting package would not validate the inference. ${ }^{33}$

31. Thanks here to an anonymous reviewer.

32. Note that the intuitively marked pattern (57) is in fact a (vacuous) Strawson entailment. A fan of Strawson entailment will presumably explain the markedness of the inference by appeal to its vacuity.

33. To elaborate, consider any possible world $w$ such that every professor at $w$ is friendly at $w$. If we assume a textbook predicate logic semantics for quantification, it follows that $\forall x(P x, F x)$ is true at $w$. Now suppose further that there is a world $w^{\prime}$ epistemically accessible from $w$ such that Jane is a professor in $w^{\prime}$ Then assuming a Kratzerian relational semantics for epistemic modals, $\diamond P j$ is true at $w$. From these two things, however, it does not in any sense follow that the nearest world $y$ to $w$ where Jane is a professor in $y$ is such that Jane is friendly in $y$. But that is what would have to follow for $P j \Rightarrow F j$ to be true at $w$, given the Stalnaker semantics for the indicative. If, as is 
The problem is arguably with the extensionality of quantification on this kind of approach. The truth of a (non-lawlike) quantified sentence is settled entirely by the world of evaluation, and has nothing to do with what is going on at alternative accessible worlds. So adding a modal sentence like (54) to (53) is not sufficient to entail a substantive modal claim like (55). What we must recognize is the (epistemically) modal dimension of quantification, and more generally, of entailment. Like epistemic modal sentences, universally quantified sentences express constraints on how states of information can be extended. If we overlook this dimension of quantification, we are apt to miss rather basic intuitively valid patterns of inference.

Another such pattern is:

\section{Modal via Universal}

$\forall x(F x, G x)$

$\diamond F a$

$\therefore \diamond G a$

Here too, it is plain that on the extensional predicate logic semantics for quantification, the inference is not validated: if you occupy a world $w$ such that $\forall x(F x$, $G x)$ is true at $w$, and moreover a world $w^{\prime}$ where $F a$ is true is accessible from $w$, it does not follow that a world $w^{\prime \prime}$ where $G a$ is true is accessible from $w$. This is another form of inference captured on the present system. ${ }^{34}$

\section{In-Scope $D e R e$}

I want to close by mentioning a second class of problems about epistemic modality de re. I believe the current framework can be extended to address these problems, but an argument for this claim, and a full treatment of the problems,

standard on these frameworks, entailment is defined in terms of preservation of truth at a world, $\{\forall x(P x, F x), \diamond P j\} \not(P j \Rightarrow F j)$.

The fundamental problem is not avoided by adopting instead a strict conditional analysis, or the restrictor analysis of conditionals given by Kratzer (1986). On neither approach would the condition on worlds corresponding to $\forall x(P x, F x), \diamond P j$ suffice to guarantee that the condition on worlds corresponding to $(P j \Rightarrow F j$ is satisfied.

It may be possible within a more traditional frameworks to recover Indicative via Universal as a pragmatic "reasonable inference" in the sense of Stalnaker (1975); but it seems to me that the balance of considerations reviewed in this paper favor an analysis rendering the inference valid in the semantically interesting sense.

34. It is also captured by the system of Yalcin (2007) as extended with quantifers (as in the appendix), not to mention the system of Groenendijk et al. (1996). The patterns of inference mentioned in this section could be added to the list of arguments discussed by Bledin (2014) in favor of an "informational" conception of logical consequence. 
is beyond the scope of the present paper. I only wish to bring these problems to light so that they can be addressed in future work. Any full discussion of epistemic modality de re must mention these problems.

Traditionally, the de re /de dicto ambiguity is modeled as a structural ambiguity, one of scope at logical form. A de re reading of a quantifier or determiner phrase is one where that expression takes wide scope relative to an intensional verb or operator, and binds a variable within the scope of that intensional expression. This is the kind of de re reading that has been in focus throughout the paper.

But it is well known that there are certain de re readings which resist characterization purely in terms of scope (Fodor 1970; Bäuerle 1983; Cresswell 1990; Percus 2000; see also von Stechow 1984; Abusch 1994; Keshet 2008a;b). One kind of example of this occurs commonly in textbooks on modal logic-usually, in the section on multiple indexing or two-dimensional semantics (see, e.g., Hughes \& Cresswell 1996; Sider 2010). To see the basic point, take:

(58) It could have been that everyone inside was outside.

On the preferred reading, this sentence is true only if there is some accessible possible world wherein all of those who are in fact inside are outside in that world. 35 We could formalize the truth-conditions of this reading with overt quantification over possible worlds as follows:

(58) is true at $w$ iff $\exists w^{\prime}\left(w R w^{\prime} \wedge \forall x\left(I x w \supset O x w^{\prime}\right)\right)$

(Using ' $I$ ' and ' $O$ ' in the obvious way to designate the relevant predicate intensions.) On this reading, the intension of inside is evaluated relative to the evaluation world of the whole sentence, rather than the possibility introduced by the modal-in this way, it is like the standard de re reading, where the quantifier phrase everyone inside is represented as quantifying into the modal-but the universal quantificational force introduced by this quantifier phrase must be outscoped by the quantificational force of the modal -in this way, it is like the standard de dicto reading. Accordingly, such readings are sometimes called "scope paradoxical". I will call this kind of reading (of a determiner phrase relative to a modal) the in-scope de re reading. The need to capture this reading is a classic motivation for two-dimensional semantics, one closely related to the standard motivations stemming from indexicals (Prior 1968; Kamp 1971; Vlach 1973; Ka-

35. Theorists interested in highlighting this reading will often insert actually into the sentence (as in 'It could have been that everyone actually inside was outside'). But as Humberstone (2011) correctly emphasizes in discussing similar examples, the relevant reading is available regardless of the presence of an overt actually. For further discussion of actually, see Yalcin (2015). 
plan 1977/1989). It is also a standard motivation for allowing world or situation variables into the formal object language we use to model natural language (for a sense of this approach, see Cresswell 1990; Percus 2000; Schlenker 2006; Keshet 2008a; von Fintel \& Heim 2011; Schwarz 2012).

Observe that one can get in-scope de re readings with a variety of modal flavors. The modal in (58), for example, can be read metaphysically, nomologically, deontically, or as an ability modal, all compatible with the in-scope de re reading remaining available. These seem to just reflect different choices for the accessibility relation $R$. Relatedly, these sentences have the in-scope de re reading:

(59) Everyone inside is permitted to be outside.

(6o) Everyone inside is able to be outside.

Now the point I want to observe is that in contrast to this, the corresponding epistemically modalized sentences do not license any coherent in-scope de re reading:

(61) \# Everyone inside might be outside.

This sentence strikes us as incapable of being true, and rings as incoherent. The intuition is that the quantifier everyone inside must be evaluated at the same world as the predicate outside. This suggests that the epistemic modal obligatorily shifts the world the subject is evaluated relative to. ${ }^{36}$

This fact is not immediately explicable from the point of view of an analysis of epistemic modals along the lines of Kratzer (1991; 2012), or any other treatment broadly in the style of an ordinary accessibility-relation based possible worlds semantics for modals. On this sort of semantics, the prediction is that (61) should have an in-scope de re reading that is true and assertable in many kinds of epistemic predicament. For example, suppose that my epistemic state, or our shared knowledge or information, leaves open two relevant possible worlds: either Sally and Steve are inside, and Rae and Richard are outside $\left(w_{1}\right)$; or Rae and Richard are inside, and Sally and Steve are outside $\left(w_{2}\right)$. Given this epistemic situation, whoever actually turns out to be inside will be such that there is an epistemically accessible world where they are outside. One pos-

36. A closely related observation is made by Williamson (2006), who notes that the modal comparative sentence 'You may be less tall now than you actually are' is "obviously false", in contrast with 'You could have been less tall now than you actually are'. He does not make the point I am making here, however, which is that epistemic modals, in contrast to other kinds of modal, do not allow coherent in-scope de re readings in certain cases. Although many of the points I make carry over to modal comparatives, I will for the most part set explicit discussion of these aside, as comparatives present considerable independent difficulties.

Note further that it is important that (61) is in the present tense. 
sibility, for instance, is that $w_{1}$ is the case, and Sally and Steve are inside. In that case, everyone inside (viz., Sally and Steve) is such that there is an epistemically accessible world where they are outside (namely, $w_{2}$ ). Likewise, mutatis mutandis, if $w_{2}$ is the case. This means that if the in-scope de re reading of the sentence were available, it would be true, given a standard relational semantics for epistemic modality. It would also be something potentially interesting and relevant to communicate: you would be conveying that your epistemic state has a certain kind of (coherent, nontrivial) property. (The property entails, for instance, that you don't know of any particular individual that he is inside.) Since this reading is not in fact available, something in the standard analyses of epistemic modality and quantification needs modification.

Note that the principle of epistemic containment (von Fintel \& Iatridou 2003) does not help here. That principle constrains the movement of quantifiers across epistemic modals. If correct, that principle would predict the absence of the ordinary, wide scope de re reading of everyone inside in (61). It does not predict the absence of the in-scope de re reading, since this reading is precisely not a reading wherein the quantifier is taking wide scope relative to the modal. (In a sense, the observation here is that the epistemic containment principle does not go far enough.)

An analogous asymmetry can be observed in conditionals. Whereas counterfactual conditional antecedents license in-scope de re readings of determiner phrases they contain, these readings are difficult to observe in the corresponding indicative conditionals. For example, on the most natural reading of the following sentence, everyone inside takes an in-scope de re reading (Percus 2000; Keshet 2008a):

(62) If everyone inside were outside, the room would be empty.

In contrast, the in-scope de re reading goes missing in the corresponding indicative conditional:

(63) \# If everyone inside is outside, the room is empty.

(See Postal 1974; Jackson 1980; 1987; Williamson 2006 for minimal pairs closely related to $\left.(62) /(63) .{ }^{37}\right)$ Naively, we might have dismissed this sentence on the simple grounds that its antecedent is inconsistent. But the availability of the inscope de re reading of everyone inside in (62) prompts us to ask why that reading is not available in (63). Why can't the intension of inside be evaluated relative to

37. These authors do not frame the issue raised by such minimal pairs as one about the absence of the in-scope de re reading. 
the evaluation world of the sentence, while the intension of outside is evaluated relative to the layer of modality introduced by the indicative conditional - as is obviously possible with the corresponding counterfactual? ${ }^{3}$

To bring the problem into greater focus, it helps to fix on a concrete theory of indicative conditionals, and to adjust the example slightly. Consider:

(64) If everyone inside were outside, everyone outside would be inside.

(65) \# If everyone inside is outside, everyone outside is inside.

There is a reading of (64) wherein both quantifiers take the in-scope de re reading. Not so for (65). Let's now observe why this is unexpected given one standard theory of indicative conditionals, namely that of Stalnaker $(1968 ; 1975)$. On Stalnaker's semantics, $(\phi \Rightarrow \psi)$ is true at a world $w$ just in case (roughly) at the nearest world $w^{\prime}$ to $w$ making $\phi$ true, $\psi$ is true. Indicatives and counterfactuals are taken to both fit this general kind of shape; but the indicative mood, Stalnaker suggests, is a conventional way of signaling that the nearest world making the antecedent true is one within the context set of the conversation.

Taking this theory for granted, suppose that the state of information described in connection with (61) above constitutes our conversational context set at the relevant level of abstraction. That is, consider the context set $\left\{w_{1}, w_{2}\right\}$, wherein $w_{1}$ is a world with Sally and Steve inside and Rae and Richard outside, and $w_{2}$ is a world where the reverse is the case. ${ }^{39}$ Now we have a situation where the missing de re reading of (65) would be true, given Stalnaker's semantics. For observe that the nearest world $w^{\prime}$ to $w_{1}$ in the context set such that everyone inside in $w_{1}$ is outside in $w^{\prime}$ is $w_{2}$; and the nearest world $w^{\prime \prime}$ to $w_{2}$ in the context set such that everyone inside in $w_{2}$ is outside in $w^{\prime \prime}$ is $w_{1}$. So the indicative conditional should be counted true, relative to our context. Indeed, we come out as already presupposing it is true. That prediction is incorrect.

The problem is not unique to Stalnaker's semantics. The problem will arise for any of the usual options for an intensional semantics for indicatives. Relatedly, the problem arises in the context of Kratzer's (1986) restrictor analysis of if-clauses, as implemented in a possible worlds semantics. On the usual way of interpreting this theory, indicative conditionals are construed as epistemic modal sentences, and the semantic role of the if-clause is to restrict the quantifi-

38. One kind of reaction to this data would be to conclude that there is in fact no layer of modality introduced by indicative conditionals: unlike their counterfactual counterparts, they do not create intensional contexts. Discussing similar examples, Jackson (1987) has this kind of reaction (cf. Postal 1974; Williamson 2006).

39. For concreteness, we might further assume that the context set reflects our common knowledge (and hence contains the actual world); and that $w_{1}, w_{2}$ are similar in all conversationally relevant respects (modulo of course the difference about who is and is not inside). 
cational force of a (perhaps covert) epistemic modal to worlds compatible with the antecedent. There is nothing in this theory which would prevent (65) from taking a true in-scope de re reading.

To summarize: epistemic modals, unlike other modals, superficially seem not to license felicitous in-scope de re readings in certain cases; and indicative conditionals, unlike counterfactuals, superficially seem not to license felicitous in-scope de re readings in certain cases. These facts remain to be explained. $4^{\circ}$

Now that the possibility of in-scope de re readings is finally in focus, we should note that a logical possibility is that the definite descriptions in sentences like (1), (2), (3) and (4) all admit of in-scope de re readings. Indeed, for all we have said, this may be the preferred reading of these definite descriptions. If (3) and (4) do admit of in-scope de re readings, then the solution developed above does not yet apply to these readings. Our analysis applies to cases of where epistemic modals take narrow scope relative to quantifiers or descriptions. But on the inscope de re reading, the epistemic modal is syntactically taking wide scope.

It is not too hard to imagine a static two-dimensional semantics capable of modeling aspects of the way in which epistemic modals interact with in-scope de re readings. ${ }^{41}$ Harder is to give a static two-dimensional semantics that can

40. Note that we have not established the blanket claim that in-scope de re readings are in general unavailable under epistemic modals. Placing (61) within an attitude construction of the appropriate sort appears to render it felicitous, as Nathan Klinedinst (personal communication, March 1, 2013) and Kai von Fintel (personal communication, October 12, 2014) have also independently observed:

(66) John thinks everyone inside might be outside.

(67) John thinks it is possible that everyone (actually) inside is outside.

-though one should like to take measures here to rule out the possibility that the quantifier is taking wide scope relative to the attitude verb. (Perhaps one could lean on independent constraints on quantifier raising, such as the constraint that quantifiers may not raise out of a tensed clause (May 1977).) Note that things are different if the subject is first-person and tense is present, as pointed out to me by John Hawthorne (personal communication, March 8, 2013) and Kai von Fintel (personal communication, October 12, 2014):

(68) \# I think everyone inside might be outside.

41. For example, relativizing extensions to pairs of worlds, we could have epistemic modals serve to shift the world parameter used to "track actuality". Thus if an ordinary non-epistemic possible modal $\bullet$ is given the following kind of semantics:

$w, v \vDash \bullet \phi$ if there is some $v^{\prime} R$-accessible from $v$ such that $w, v^{\prime} \vDash \phi$

where the first (unshifted) world parameter is used to capture de re readings of expressions within the scope of the modal, we could have epistemics shift this parameter:

$w, v \vDash \diamond \phi$ if there is some $v^{\prime}$ epistemically accessible from $v$ such that $v^{\prime}, v^{\prime} \vDash \phi$

This double-shift would compel in-scope de re determiner phrases to be evaluated at the same world as the main predicate in their clause. (Cf. Weatherson 2001 on indicatives.) 
handle both the facts about in-scope de re readings and also the facts about binding in discussed above.

To begin to accommodate these data in a dynamic setting, the system developed above first must be extended so that it is capable of representing counterfactual conditionals and counterfactual quantified sentences (such as 'Everyone rich could have been poor'), in such a way as to allow for representation of the felicitous in-scope de re readings we observe in these environments. Work on dynamic approaches to counterfactuals by von Fintel (2001), Veltman (2005), Asher and McCready (2007), Gillies (2007), and Moss (2012) will be relevant here. We will likely need to enrich our modeling language with world or situation variables; here Keshet (2008b) and Schwarz (2012) make key advances. Further, a dynamic account of definite descriptions in interaction with counterfactual contexts will need to reckon with the facts discussed by Rothschild (2007).

\section{Closing}

There is nothing to fear about quantifying into modal contexts. But the way this works in the case of epistemic modality is distinctive. The puzzles of epistemic modality de re present a challenge for standard ways of thinking about the interaction of modals with quantifiers and descriptions. Our solutions took the form of a dynamic compositional semantics. The dynamic semantics we have given is of a rather restrained variety. There are no discourse referents. In the context of the assumption of something like consecutive update idempotence, the kinds of failures of idempotence and commutativity standardly allowed in other dynamic systems are prohibited. What we have seen is that a dynamic framework can be illuminating and explanatory even in abstraction from these more traditional motivations for going dynamic.

We have not shown that a compelling static competitor to the present theory could not be developed, however. A natural question prompted by the preceding is: what kind of (non-dynamic) revision to a textbook static intensional semantics for a quantified modal language could resolve the problems reviewed? The question is of interest if we want a more complete understanding of the extent to which the facts about epistemic modality de re support an especially dynamic approach to meaning.

Whatever the best static competitor account is, it seems unlikely to include any of the most familiar ways of implementing a Fregean theory of definite descriptions, for reasons noted. No doubt the Fregean view can be retooled. It remains to be seen how.

In other work (Yalcin 2007; 2011; 2012a) I have articulated a broadly expressivist understanding of the role of epistemic modal discourse, in the process 
mostly working with a certain static semantics for epistemic modal talk. I do not view the dynamic semantics explored here as in any tension with that expressivist viewpoint. On the contrary, the semantics above seems to me perfectly congenial to the expressivist perspective I favor. (See Yalcin 2012a for more discussion of the relation between expressivism and compositional semantics.)

Pre-Kripkean suspicion about quantifying into modal contexts is perhaps somewhat more intelligible in light of the kinds of examples discussed above. Those suspicions may have been inchoately tracking, at least to some extent, epistemic modality de re. We should close by stressing that this jargon of "epistemic modality de $r e$ " is apt to mislead if not used advisedly. If anything is clear from the above, it is that a thing does not have epistemically modal properties in abstraction from the way that it is specified.

\section{Appendix}

\section{A.1. Trouble for Yalcin (2007), MacFarlane (2011)}

Yalcin (2007) and MacFarlane (2011) contain essentially the same compositional semantic clauses for epistemic modals (unsurprisingly, as the former work was building on earlier drafts of the latter; cf. also Van Rooij 2005). But the formal language discussed by Yalcin (2007) is sentential, whereas MacFarlane works explicitly with a quantified language. The most natural extension of the semantics defended by Yalcin (2007) with quantifiers just is the kind of semantics given by MacFarlane. Here is the semantics (with models, variable assignments, and modified variable assignments defined as above):

$$
\begin{aligned}
& \mathcal{M}, w, s \vDash_{g} \mathcal{F}_{i}^{k}\left(x_{1}, \ldots, x_{k}\right) \text { iff }\left\langle g\left(x_{1}\right), \ldots, g\left(x_{k}\right)\right\rangle \in V\left(\mathcal{F}_{i}^{k}, w\right) \\
& \mathcal{M}, w, s \vDash_{g} \neg \phi \text { iff } \mathcal{M}, w, s, \nvdash_{g} \phi \\
& \mathcal{M}, w, s \vDash_{g}(\phi \wedge \psi) \text { iff } \mathcal{M}, w, s \vDash_{g} \phi \text { and } \mathcal{M}, w, s \vDash_{g} \psi \\
& \mathcal{M}, w, s \vDash_{g} \diamond \phi \text { iff there is some } w^{\prime} \in s: \mathcal{M}, w^{\prime}, s \vDash_{g} \phi \\
& \mathcal{M}, w, s \models_{g} \exists x_{i}(\phi, \psi) \text { iff there is some } d \in D_{\mathcal{M}}: \mathcal{M}, w, s \models_{g\left[x_{i} / d\right]}(\phi \wedge \psi)
\end{aligned}
$$

It is easy to see that neither account predicts any defect in

$$
\text { (69) } \exists x(\neg F x, \diamond F x)
$$

By a trivial calculation, the truth-conditions are predicted to be: 
$\mathcal{M}, w, s \vDash_{g} \exists x(\neg F x, \diamond F x)$ iff there is some $d \in D_{\mathcal{M}}$ such that $d \notin V_{\mathcal{M}}(F, w)$ and there exists some $w^{\prime} \in s$ such that $d \in V_{\mathcal{M}}\left(F, w^{\prime}\right)$

This is a perfectly coherent condition on points of evaluation. So no defect is predicted.

Although their compositional semantics are alike, Yalcin (2007) defines consequence in a different way than MacFarlane (2011). MacFarlane defines it in the standard Tarskian way, in terms of preserving truth at a point of evaluation, whereas Yalcin (2007) defines it as an "incorporation-preserving" relation: sentences are ultimately understood to determine constraints on information states, and consequence is a matter of the constraints corresponding to the premises guaranteeing that the constraint expressed by the conclusion is satisfied. While this difference allowed me to classify closed epistemic contradictions as bonafide contradictions, it does not assist with (69). The apparatus of Yalcin (2007) predicts that (69) expresses the following constraint on information states:

\{s : for all $w \in s$, there is some $d \in D_{\mathcal{M}}$ such that $d \notin V_{\mathcal{M}}(F, w)$ and there exists some $w^{\prime} \in s$ such that $\left.d \in V_{\mathcal{M}}\left(F, w^{\prime}\right)\right\}$

This is a coherent constraint. Thus Yalcin (2007) predicts no defect with the sentence. The basic structure of the problem here is the same when we consider universal quantifiers and definite descriptions.

\section{A.2. Duality}

Modulo the addition of further constraints on the compositional semantics (such as the consecutive update idempotence requirement discussed in Section 9), the quantifiers defined in Section 7 of the above semantics are duals: one could be defined in terms of the other and negation. To see that $\neg \exists x(\phi, \neg \psi) \equiv \forall x(\phi, \psi)$, we can unpack the semantics for $\neg \exists x(\phi, \neg \psi)$ and apply some elementary set theory:

$$
\begin{aligned}
s[\neg \exists x(\phi, \neg \psi)]^{g} & =s-s[\exists x(\phi, \neg \psi)]^{g} \\
& \left.=s-\bigcup_{d \in D} s[\phi \wedge \neg \psi)\right]^{g[x / d]} \\
& =s-\bigcup_{d \in D} s[\phi]^{g[x / d]}[\neg \psi]^{g[x / d]} \\
& =s-\bigcup_{d \in D} s[\phi]^{g[x / d]}-s[\phi]^{g[x / d]}[\psi]^{g[x / d]} \\
& =s-\bigcup_{d \in D} s-\left(s[\phi]^{g[x / d]}-s[\phi]^{g[x / d]}[\psi]^{g[x / d]}\right) \\
& =\bigcap_{d \in D} s-\left(s[\phi]^{g[x / d]}-s[\phi]^{g[x / d]}[\psi]^{g[x / d]}\right) \\
& \left.=\bigcap_{d \in D} s[\phi \rightarrow \psi)\right]^{g[x / d]} \\
& =s[\forall x(\phi, \psi)]^{g}
\end{aligned}
$$


We can take the same general approach to see that $\neg \forall x(\phi, \neg \psi) \equiv \exists x(\phi, \psi)$ :

$$
\begin{aligned}
s[\neg \forall x(\phi, \neg \psi)]^{g} & =s-s[\forall x(\phi, \neg \psi)]^{g} \\
& \left.=s-\bigcap_{d \in D} s[\phi \rightarrow \neg \psi)\right]^{g[x / d]} \\
& =s-\bigcap_{d \in D} s-\left(s[\phi]^{g[x / d]}-s[\phi]^{g[x / d]}[\neg \psi]^{g[x / d]}\right) \\
& =s-\bigcap_{d \in D} s-\left(s[\phi]^{g[x / d]}-\left(s[\phi]^{g[x / d]}-s[\phi]^{g[x / d]}[\psi]^{g[x / d]}\right)\right) \\
& =s-\bigcap_{d \in D} s-\left(s[\phi]^{g[x / d]}[\psi]^{g[x / d]}\right) \\
& =\bigcup_{d \in D} s-\left(s-\left(s[\phi]^{g[x / d]}[\psi]^{g[x / d]}\right)\right) \\
& =\bigcup_{d \in D} s[\phi]^{g[x / d]}[\psi]^{g[x / d]} \\
& =\bigcup_{d \in D} s[\phi \wedge \psi]^{g[x / d]} \\
& =s[\exists x(\phi, \psi)]^{g}
\end{aligned}
$$

\section{A.3. Coherence of Marked Sentences}

We observe that

(28) ?? Some person who might be infected is not infected.

$$
\exists x(\diamond I x, \neg I x)
$$

is coherent given the definitions of Section $7-$ meaning that (28) has nonempty fixed points. Consider an information state $s=\left\{w, w^{\prime}\right\}$, with objects $d_{1}$ and $d_{2}$ such that $V(I, w)=\left\{d_{1}\right\}$ and $V\left(I, w^{\prime}\right)=\left\{d_{2}\right\}$. We observe that $s[(28)]=s$.

$$
\begin{aligned}
& s[\exists x(\diamond I x, \neg I x)]^{g}=\bigcup_{d \in D} s[\diamond I x \wedge \neg I x]^{g[x / d]} \\
& s[\exists x(\diamond I x, \neg I x)]^{g}=\bigcup_{d \in D} s[\diamond I x]^{g[x / d]}[\neg I x]^{g[x / d]} \\
& s[\exists x(\diamond I x, \neg I x)]^{g}=\bigcup_{d \in D}\left\{w \in s: s[I x]^{g[x / d]} \neq \varnothing\right\}[\neg I x]^{g[x / d]} \\
& s[\exists x(\diamond I x, \neg I x)]^{g}=\bigcup_{d \in D}\left\{w \in s:\left\{w^{\prime} \in s: d \in V\left(I, w^{\prime}\right)\right\} \neq \varnothing\right\}[\neg I x]^{g[x / d]}
\end{aligned}
$$

At this stage we can observe that for values of the metavariable $d$ other than $d_{1}$ and $d_{2},\left\{w \in s:\left\{w^{\prime} \in s: d \in V\left(I, w^{\prime}\right)\right\} \neq \emptyset\right\}$ is the empty set. Any further update of the empty set is the empty set, so we can set these values of $d$ aside. By contrast, if $d$ is $d_{1}$ or $d_{2},\left\{w \in s:\left\{w^{\prime} \in s: d \in V\left(I, w^{\prime}\right)\right\} \neq \emptyset\right\}=s$. The above therefore reduces to:

$$
\begin{aligned}
& s[\exists x(\diamond I x, \neg I x)]^{g}=s[\neg I x]^{g\left[x / d_{1}\right]} \cup s[\neg I x]^{g\left[x / d_{2}\right]} \\
& s[\exists x(\diamond I x, \neg I x)]^{g}=\left\{w^{\prime}\right\} \cup\{w\}=s
\end{aligned}
$$


Thus (28) has a nonempty fixed point in s, hence is coherent.

The basic observation here is due to Aloni (2001). Discussing intersentential analogues of the present examples (e.g., 'Someone might be the culprit. She is not the culprit.'), Aloni observes that discourses of the form of $\exists x \diamond F x \wedge \neg F x$ are coherent in the technical sense for systems like that of Groenendijk et al. (1996), for essentially the sort of reason just highlighted.

\section{Acknowledgements}

I have been presenting versions of this work since early 2013. Thanks to audiences at Oxford, Konstanz, UCSC, UCSD, MIT, Stanford's CSLI, the Hebrew University of Jerusalem, and Rutgers, and to Pranav Anand, Adrian Brasoveanu, John Campbell, Simon Charlow, Jonathan Cohen, Kai von Fintel, Danny Fox, John Hawthorne, Matthias Jenny, Ezra Keshet, John MacFarlane, Matt Mandelkern, Vann McGee, Marie-Christine Meyer, Sarah Moss, Declan Smithies, Robert Stalnaker, Johan van Benthem, and Stephen Yablo. Thanks also to the participants in my seminars at Berkeley in 2014 and 2015. Special thanks to Wesley Holliday and Daniel Rothschild for extensive discussion, and to Simon Goldstein for key suggestions.

\section{References}

Abusch, Dorit (1994). The Scope of Indefinites. Natural Language Semantics, 2 (2), 83-135. http://dx.doi.org/10.1007/BF01250400

Aloni, Maria (2001). Quantification Under Conceptual Covers. (Unpublished doctoral dissertation). University of Amsterdam.

Anand, Pranav and Valentine Hacquard (2013). Epistemics and Attitudes. Semantics and Pragmatics, 6 (8), 8-1. http://dx.doi.org/10.3765/sp.6.8

Asher, Nicholas and Eric McCready (2007). Were, Would, Might and a Compositional Account of Counterfactuals. Journal of Semantics, 24 (2), 93-129. http://dx.doi. org/10.1093/jos/ffl013

Barwise, Jon and John Perry (1983). Situations and Attitudes. MIT Press.

Bäuerle, Rainer (1983). Pragmatisch-Semantische Aspekte der NP-Interpretation. In Manfeld Faust, Roland Harweg, Werner Lehfeldt, and G"otz Wienold (Eds.), Allgemeine Sprachwissenschaft, Sprachtypologie und Textlinguistik (121-131, Vol. 121). G. Narr.

Beaver, David (2001). Presupposition and Assertion in Dynamic Semantics. Studies in Logic, Language and Information. CSLI Publications. http://dx.doi. org/10.1023/A:1008371413822

Bledin, Justin (2014). Logic Informed. Mind, 130 (490), 277-316. http://dx.doi.org/10.1093/ $\operatorname{mind} /$ fzu073 
Chierchia, Gennaro (1992). Anaphora and Dynamic Binding. Linguistics and Philosophy, 15 (2), 111-183. http://dx.doi.org/10.1007/BF00635805

Chierchia, Gennaro (1995). Dynamics of Meaning: Anaphora, Presupposition, and the Theory of Grammar. University of Chicago Press. http://dx.doi.org/10.7208/chicago/9780226104515.001.0001

Cresswell, Max (1990). Entities and Indices. Kluwer Academic Publishers. http://dx.doi. org/10.1007/978-94-009-2139-9

DeRose, Keith (1991). Epistemic Possibilities. Philosophical Review, 100 (4), 581-605. http:// dx.doi.org/10.2307/2185175

Dowell, Janice L. (2011). A Flexible Contextualist Account of Epistemic Modals. Philosophers' Imprint, 11 (14), 1-25.

Egan, Andy (2007). Epistemic Modals, Relativism and Assertion. Philosophical Studies, 133 (1), 1-22. http://dx.doi.org/10.1007/s11098-006-9003-x

Elbourne, Paul (2005). Situations and Individuals. MIT Press.

Elbourne, Paul (2013). Definite Descriptions. Oxford University Press. http://dx.doi. org/10.1093/acprof:oso/9780199660193.001.0001

Fara, Delia (2001). Descriptions as Predicates. Philosophical Studies, 102 (1), 1-42. http:// dx.doi.org/10.1023/A:1010379409594

von Fintel, Kai (1999). NPI Licensing, Strawson Entailment, and Context Dependency. Journal of Semantics, 16 (2), 97-148. http://dx.doi.org/10.1093/jos/16.2.97

von Fintel, Kai (2001). Counterfactuals in a Dynamic Context. In Ken Kenstowicz (Ed.), Ken Hale: A Life in Language (123-152). MIT Press.

von Fintel, Kai and Anthony Gillies (2008). CIA Leaks. Philosophical Review, 117 (1), 7798. http://dx.doi.org/10.1215/00318108-2007-025

von Fintel, Kai and Anthony Gillies (2011). 'Might' Made Right. In Andy Egan and Brian Weatherson (Eds.), Epistemic Modality (108-130). Oxford University Press. http:// dx.doi.org/10.1093/acprof:oso/9780199591596.003.0004

von Fintel, Kai and Irene Heim (2011). Intensional Semantics Lecture Notes. MIT.

von Fintel, Kai and Sabine Iatridou (2003). Epistemic Containment. Linguistic Inquiry, 34 (2), 173-98. http://dx.doi.org/10.1162/002438903321663370

von Fintel, Kai and Lisa Matthewson (2008). Universals in Semantics. The Linguistic Review, 25 (1-2), 139-201. http://dx.doi.org/10.1515/tlir.2008.004

Fodor, Janet Dean (1970). The Linguistic Description of Opaque Contents. (Doctoral dissertation, Massachusetts Institute of Technology). Retrieved from http://dspace.mit.edu/ bitstream/handle/1721.1/12970/26079066-MIT.pdf.

Frege, Gottlob (1892). On Sinn and Bedeutung. In Michael Beaney (Ed.), The Frege Reader (151-71). Trans. Max Black. Blackwell.

Gillies, Anthony (2004). Epistemic Conditionals and Conditional Epistemics. Noûs, 38 (4), 585-616. http://dx.doi.org/10.1111/j.0029-4624.2004.00485.x

Gillies, Anthony (2007). Counterfactual Scorekeeping. Linguistics and Philosophy, 30 (3), 329-36o. http://dx.doi.org/10.1007/s10988-007-9018-6

Groenendijk, Jeroen and Martin Stokhof (1991a). Two Theories of Dynamic Semantics. In Logics in AI (55-64), Vol. 478 of Lectures Notes in Computer Science. Springer. http:// dx.doi.org/10.1007/bfb0018433

Groenendijk, Jeroen and Martin Stokhof (1991b). Dynamic Predicate Logic. Linguistics and Philosophy, 14 (1), 39-100. http://dx.doi.org/10.1007/BF00628304 
Groenendijk, Jeroen, Martin Stokhof, and Frank Veltman (1996). Coreference and Modality. In Shalom Lappin (Ed.), Handbook of Contemporary Semantic Theory (179-213). Blackwell.

Hacquard, Valentine (2006). Aspects of Modality. (Doctoral dissertation, Massachusetts Institute of Technology). Retrieved from http://dspace.mit.edu/bitstream/ handle/1721.1/37421/123084384-MIT.pdf.

Hawthorne, John (2007). Eavesdroppers and Epistemic Modals. Philosophical Issues, 17 (1), 92-101. http://dx.doi.org/10.1111/j.1533-6077.2007.00124.x

Heim, Irene (1982). The Semantics of Definite and Indefinite Noun Phrases. (Doctoral dissertation, University of Massachusetts). Retrieved from http://semanticsarchive.net/ Archive/Tk0ZmYyY/heim-1982-pp-392-3.pdf.

Heim, Irene (1983). On the Projection Problem for Presuppositions. In Michael Barlow, Daniel P. Flickinger, and Michael T. Wescoat (Eds.), Proceedings, Second West Coast Conference on Formal Linguistics (114-25). Stanford Linguistics Association.

Heim, Irene (1992). Presupposition Projection and the Semantics of Attitude Verbs. Journal of Semantics, 9 (3), 183-221. http://dx.doi.org/10.1093/jos/9.3.183

Heim, Irene and Angelika Kratzer (1998). Semantics in Generative Grammar. Blackwell.

Hintikka, Jaakko (1962). Knowledge and Belief: An Introduction to the Logic of Two Notions. Cornell University Press.

Hughes, George E. and Max J. Cresswell (1996). A New Introduction to Modal Logic. Routledge.

Humberstone, Lloyd (2011). The Connectives. MIT Press.

Huvenes, Torfinn (2015). Epistemic Modals and Credal Disagreement. Philosophical Studies, 172 (4), 987-1011. http://dx.doi.org/10.1007/s11098-014-0334-8

Jackson, Frank (1980). Conditionals and Possibilia. In Proceedings of the Aristotelian Society, 81, 125-137. JSTOR.

Jackson, Frank (1987). Conditionals. Blackwell.

Kamp, Hans (1971). Formal Properties of 'Now'. Theoria, 37 (3), 227-273. http://dx.doi. org/10.1111/j.1755-2567.1971.tb00071.x

Kamp, Hans (1981). A Theory of Truth and Semantic Representation. In Jeroen A. Groenendijk, Theo Janssen, and Martin Stokhof (Eds.), Formal Methods in the Study of Language (277-322). Mathematisch Centrum, University of Amsterdam.

Kaplan, David (1977/1989). Demonstratives. In Joseph Almog, John Perry, and Howard Wettstein (Eds.), Themes from Kaplan (481-563). Oxford University Press.

Kaplan, David (1989). Afterthoughts. In Joseph Almog, John Perry, and Howard Wettstein (Eds.), Themes from Kaplan (565-614). Oxford University Press.

Karttunen, Lauri (1969). Discourse Referents. In Proceedings of the 1969 Conference on Computational Linguistics (1-38). Association for Computational Linguistics. http:// dx.doi.org/10.3115/990403.990487

Keshet, Ezra (2008a). Good Intensions: Paving Two Roads to a Theory of the de re/de dicto Distinction. (Doctoral dissertation, Massachusetts Institute of Technology). Retrieved from http://dspace.mit.edu/bitstream/handle/1721.1/45622/320472279-MIT.pdf.

Keshet, Ezra (2008b). Only the Strong: Restricting Situation Variables. In Proceedings of SALT, 18, 483-495.

Klinedinst, Nathan and Daniel Rothschild (2015). Quantified Epistemic Modality.

Knobe, Joshua and Seth Yalcin (2014). Epistemic Modals and Context: Experimental Data. Semantics and Pragmatics, 7 (10), 1-21. http://dx.doi.org/10.3765/sp.7.10 
Kratzer, Angelika (1981). The Notional Category of Modality. In Hans-Ju“rgen Eikmeyer and Hannes Rieser (Eds.), Words, Worlds, and Contexts, New Approaches to Word Semantics (38-74). Walter de Gruyter. http://dx.doi.org/10.1515/9783110842524-004

Kratzer, Angelika (1986). Conditionals. In Anne M. Farley, Peter Farley, and Karl Eric McCollough (Eds.), Papers from the Parasession on Pragmatics and Grammatical Theory (1-15). Chicago Linguistics Society.

Kratzer, Angelika (1991). Modality. In Arnim von Stechow and Dieter Wunderlich (Eds.), Semantics: An International Handbook of Contemporary Research (639-50). de Gruyter.

Kratzer, Angelika (2012). Modals and Conditionals: New and Revised Perspectives. Oxford University Press. http://dx.doi.org/10.1093/acprof:oso/9780199234684.001.0001

Kripke, Saul (1980). Naming and Necessity. Harvard University Press. (Reprinted from Semantics of Natural Language, pp. 253-355, by Gilbert Harman and Donald Davidson, Eds., 1972, D. Reidel Publishing Co.)

Landman, Fred (1990). Partial Information, Modality, and Intentionality. In Philip Hanson (Ed.), Information, Language, and Cognition (247-284). University of British Columbia Press.

Lewis, David K. (1979). Scorekeeping in a Language Game. Journal of Philosophical Logic, 8 (1), 339-59. http://dx.doi.org/10.1007/978-3-642-67458-7_12

MacFarlane, John (2011). Epistemic Modals are Assessment-Sensitive. In Andy Egan and Brian Weatherson (Eds.), Epistemic Modality (144-78). Oxford University Press. http://dx.doi.org/10.1093/acprof:oso/9780199591596.003.0006

MacFarlane, John (2014). Assessment Sensitivity: Relative Truth and its Applications. Oxford University Press. http://dx.doi.org/10.1093/acprof:oso/9780199682751.001.0001

May, Robert (1977). The Grammar of Quantification. (Doctoral dissertation, Massachusetts Institute of Technology). Retrieved from http://dspace.mit.edu/bitstream/ handle/1721.1/16287/05625047-MIT.pdf.

Moss, Sarah (2012). On the Pragmatics of Counterfactuals. Nô̂s, 46 (3), 561-586. http:// dx.doi.org/10.1111/j.1468-0068.2010.00798.x

Moss, Sarah (2015). On the Semantics and Pragmatics of Epistemic Vocabulary. Semantics and Pragmatics, 8 (5), 1-81. http://dx.doi.org/10.3765/sp.8.5

Percus, Orin (2000). Constraints on Some Other Variables in Syntax. Natural Language Semantics, 8 (3), 173-229. http://dx.doi.org/10.1023/A:1011298526791

Postal, Paul M. (1974). On Certain Ambiguities. Linguistic Inquiry, 5 (3), 367-424.

Prior, Arthur (1968). Now. Noûs, 2 (2), 101-119. http://dx.doi.org/10.2307/2214699

Rieppel, Michael (2013). The Double Life of 'The Mayor of Oakland'. Linguistics and Philosophy, 36 (5), 417-446. http://dx.doi.org/10.1007/s10988-013-9141-5

Rothschild, Daniel (2007). Presuppositions and Scope. The Journal of Philosophy, 104 (2), 71-106.

Rothschild, Daniel (2011). Explaining Presupposition Projection with Dynamic Semantics. Semantics and Pragmatics, 4 (3), 1-43. http://dx.doi.org/10.3765/sp.4.3

Rothschild, Daniel and Seth Yalcin (in press). On the Dynamics of Conversation. Noûs.

Russell, Bertrand (1905). On Denoting. Mind, 14 (56), 479-493. http://dx.doi.org/10.1093/ mind/XIV.4.479

Schlenker, Philippe (2006). Ontological Symmetry in Language: A Brief Manifesto. Mind $\mathcal{E}$ Language, 21 (4), 504-539. http://dx.doi.org/10.1111/j.1468-0017.2006.00288.x

Schwarz, Florian (2009). Two Types of Definites in Natural Language. (Unpublished doctoral dissertation). University of Massachusetts, Amherst. 
Schwarz, Florian (2012). Situation Pronouns in Determiner Phrases. Natural Language Semantics, 20 (4), 431-475. http://dx.doi.org/10.1007/s11050-012-9086-1

Sider, Theodore (2010). Logic for Philosophy. Oxford University Press.

Stalnaker, Robert (1968). A Theory of Conditionals. In Nicholas Rescher (Ed.), Studies in Logical Theory (98-112). Basil Blackwell. http://dx.doi.org/10.1007/978-94-009-91170_2

Stalnaker, Robert (1970). Pragmatics. Synthese, 22 (1-2), 272-89. http://dx.doi.org/10.1007/ BF00413603

Stalnaker, Robert (1974). Pragmatic Presuppositions. In Milton K. Munitz and Peter Unger (Eds.), Semantics and Philosophy (197-214). New York University Press.

Stalnaker, Robert (1975). Indicative Conditionals. Philosophia, 5 (3), 269-286. http://dx.doi. org/10.1007/BF02379021

Stalnaker, Robert (1978). Assertion. In Peter Cole (Ed.), Syntax and Semantics 9: Pragmatics (315-332). Academic Press.

Stalnaker, Robert (2002). Common Ground. Linguistics and Philosophy, 25 (5-6), 701-21. http://dx.doi.org/10.1023/A:1020867916902

Stalnaker, Robert (2014). Context. Oxford University Press. http://dx.doi.org/10.1093/acp rof:oso/9780199645169.001.0001

Starr, William (2014). A Uniform Theory of Conditionals. Journal of Philosophical Logic, 43 (6), 1019-1064. http://dx.doi.org/10.1007/s10992-013-9300-8

Stephenson, Tamina C. (2007). Judge Dependence, Epistemic Modals, and Predicates of Personal Taste. Linguistics and Philosophy, 30 (4), 487-525. http://dx.doi.org/10.1007/ s10988-008-9023-4

Swanson, Eric (2006). Interactions with Context. (Doctoral dissertation, Massachusetts Institute of Technology). Retrieved from http://dspace.mit.edu/bitstream/ handle/1721.1/37356/123190034-MIT.pdf.

Swanson, Eric (2010). On Scope Relations between Quantifiers and Epistemic Modals. Journal of Semantics, 27 (4), 529-540. http://dx.doi.org/10.1093/jos/ffq010

Szabó, Zoltán Gendler (2000). Descriptions and Uniqueness. Philosophical Studies, 101 (1), 29-57. http://dx.doi.org/10.1023/A:1026437211756

Teller, Paul (1972). Epistemic Possibility. Philosophia, 2 (4), 303-20. http://dx.doi. org/10.1007/BF02381591

Thomason, Richmond (1969). Modal Logic and Metaphysics. In Karel Lambert (Ed.), The Logical Way of Doing Things (119-146). Yale University Press.

Thomason, Richmond and Robert Stalnaker (1968). Modality and Reference. Nous, 2 (4), 359-372. http://dx.doi.org/10.2307/2214461

van Benthem, Johan (1996). Exploring Logical Dynamics. CSLI Publications.

Van Rooij, Robert (2005). A Modal Analysis of Presupposition and Modal Subordination. Journal of Semantics, 22 (3), 281-305. http://dx.doi.org/10.1093/jos/ffh026

Veltman, Frank (1984). Data Semantics. In Jeroen Groenendijk, Theo M. V. Janssen, and Martin Stokhof (Eds.), Truth, Interpretation, and Information (43-63). Foris. http:// dx.doi.org/10.1515/9783110867602.43

Veltman, Frank (1985). Logics for Conditionals. (Unpublished doctoral dissertation). University of Amsterdam.

Veltman, Frank (1996). Defaults in Update Semantics. Journal of Philosophical Logic, 25 (3), 221-61. http://dx.doi.org/10.1007/bf00248150 
Veltman, Frank (2005). Making Counterfactual Assumptions. Journal of Semantics, 22 (2), 159-180. http://dx.doi.org/10.1093/jos/ffh022

Vlach, Frank (1973). "Now" and "Then": a Formal Approach in the Logic of Tense Anaphora. (Unpublished doctoral dissertation). University of California, Los Angeles.

von Stechow, Arnim (1984). Comparing Semantic Theories of Comparison. Journal of Semantics, 3 (1), 1-77. http://dx.doi.org/10.1093/jos/3.1-2.1

Weatherson, Brian (2001). Indicative and Subjunctive Conditionals. Philosophical Quarterly, 51 (203), 200-216. http://dx.doi.org/10.1111/j.0031-8094.2001.00224.x

Willer, Malte (2010). Modality in Flux. (Doctoral dissertation, University of Texas). Retrieved from http://gradworks.umi.com/3484425.pdf.

Willer, Malte (2013). Dynamics of Epistemic Modality. Philosophical Review, 122 (1), 4592. http://dx.doi.org/10.1215/00318108-1728714

Willer, Malte (2014). Dynamic Thoughts on Ifs and Oughts. Philosophers' Imprint, 14 (28), $1-30$.

Williamson, Timothy (2006). Indicative Versus Subjectunctive Conditionals, Congruential Versus Non-Hyperintensional Contexts. Philosophical Issues, 16 (1), 310-333. http://dx.doi.org/10.1111/j.1533-6077.2006.00116.x

Yablo, Stephen (2011). A Problem about Permission and Possibility. In Andy Egan and Brian Weatherson (Eds.), Epistemic Modality (270-294). Oxford University Press.

Yalcin, Seth (2007). Epistemic Modals. Mind, 116 (464), 983-1026. http://dx.doi.org/10.1093/ acprof:oso/9780199591596.003.0010

Yalcin, Seth (2011). Nonfactualism about Epistemic Modality. In Andy Egan and Brian Weatherson (Eds.), Epistemic Modality (295-332). Oxford University Press. http:// dx.doi.org/10.1093/acprof:oso/9780199591596.003.0011

Yalcin, Seth (2012a). Bayesian Expressivism. Proceedings of the Aristotelian Society, 112 (2), 123-16o. http://dx.doi.org/10.1111/j.1467-9264.2012.00329.x

Yalcin, Seth (2012b). Context probabilism. In Maria Aloni, Vadim Kimmelman, Floris Roelofsen, Galit Weidman Sassoon, Katrin Schulz, and Matthijs Westera (Eds.), Proceedings of the Eighteenth Amsterdam Colloquium (12-21), Vol. 7218 of Lecture Notes in Computer Science. Springer. http://dx.doi.org/10.1007/978-3-642-31482-7_2

Yalcin, Seth (2012c). A Counterexample to Modus Tollens. Journal of Philosophical Logic, 41 (6), 1001-1024. http://dx.doi.org/10.1007/s10992-012-9228-4

Yalcin, Seth (2015). Actually, Actually. Analysis, 75 (2), 185-191. http://dx.doi.org/10.1093/ analys/anv021

Yanovich, Igor (2014). Standard Contextualism Strikes Back. Journal of Semantics, 30 (1), 67-114. http://dx.doi.org/10.1093/jos/ffs022 
